\title{
A Guide to Selected Resources on Memorization Techniques for Pianists: An Annotated Bibliography
}

Silvia A. Atmadja

West Virginia University

Follow this and additional works at: https://researchrepository.wvu.edu/etd

\section{Recommended Citation}

Atmadja, Silvia A., "A Guide to Selected Resources on Memorization Techniques for Pianists: An Annotated Bibliography" (2012). Graduate Theses, Dissertations, and Problem Reports. 4827.

https://researchrepository.wvu.edu/etd/4827

This Dissertation is protected by copyright and/or related rights. It has been brought to you by the The Research Repository @ WVU with permission from the rights-holder(s). You are free to use this Dissertation in any way that is permitted by the copyright and related rights legislation that applies to your use. For other uses you must obtain permission from the rights-holder(s) directly, unless additional rights are indicated by a Creative Commons license in the record and/ or on the work itself. This Dissertation has been accepted for inclusion in WVU Graduate Theses, Dissertations, and Problem Reports collection by an authorized administrator of The Research Repository @ WVU.

For more information, please contact researchrepository@mail.wvu.edu. 


\title{
A Guide to Selected Resources on
}

\section{Memorization Techniques for Pianists: An Annotated Bibliography}

\author{
Silvia A. Atmadja \\ Research project submitted to the \\ College of Creative Arts at West Virginia University \\ in partial fulfillment of the requirements \\ for the degree of \\ Doctor of Musical Arts \\ in \\ Performance: Piano
}

\author{
D.M.A. Committee \\ Dr. James Miltenberger, Chair \\ Dr. Lucy Mauro, Research Advisor \\ Dr. Keith Jackson \\ Dr. David Taddie \\ Dr. James Shumway
}

\author{
School of Music \\ Morgantown, West Virginia
}

2012

Keywords: Bibliography, Piano, Memorization, Memorizing Piano Music 


\begin{abstract}
A Guide to Selected Resources on

Memorization Techniques for Pianists: An Annotated Bibliography
\end{abstract}

\title{
Silvia A. Atmadja
}

This research project provides reviews of resources for pianists, performers, teachers and students, striving to deepen their knowledge of memorization techniques and explore different methods of memorizing piano music, and for scholars pursuing further research on this important topic. Readers will find resources that discuss the topic from the musical and psychological standpoints, but not a scientific approach to brain and memorization. Resources include books, journal articles, and theses/dissertations that are written in English from the 1890s through the first decade of the $21^{\text {st }}$ century. 


\section{TABLE OF CONTENTS}

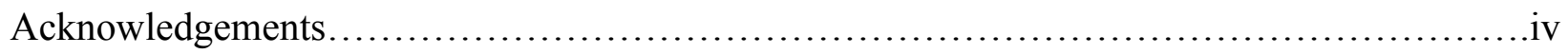



Background of the Problem.................................................

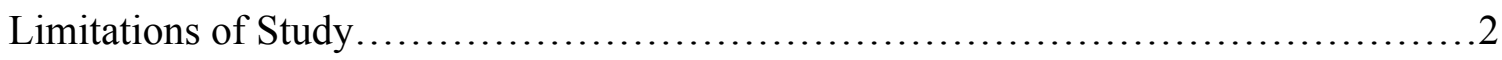

Method of Research............................................................

Chapter II - Annotated Bibliography: Books........................................4

Chapter III - Annotated Bibliography: Articles.................................... 12

Chapter IV - Annotated Bibliography: Theses/Dissertations........................... 31

Chapter V - Summary and Conclusion............................................ 38

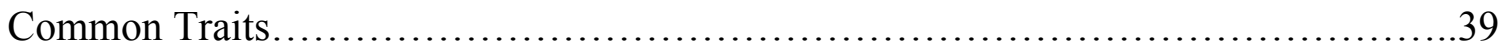

A Rise of Interest and Recent Development in the Research for the Past Decade........41

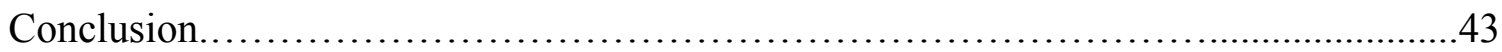

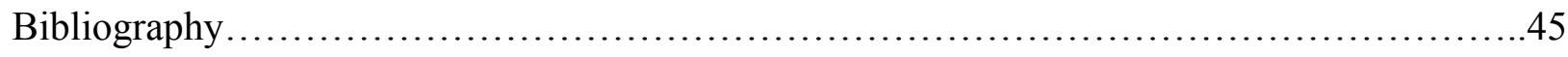




\section{ACKNOWLEDGEMENTS}

I would like to express my deepest gratitude to Dr. James Miltenberger, for his endless support throughout my study at West Virginia University, and Dr. Lucy Mauro, for her dedication and personal time spent on this project. I would also like to thank Dr. David Taddie, Dr. Keith Jackson, and Dr. James Shumway for their guidance and willingness to serve on my doctoral committee. I have been blessed with a wonderful family and friends and I cannot thank them enough for all their prayers and encouragement. Christopher Hoffman is the best husband I could ever ask for. I would have not been able to complete this project without his love and patience. 


\section{CHAPTER I}

\section{Introduction}

\section{Background of the Problem}

Memorization is an integral part of learning and performing music in a pianist's life. Pianists memorize their music for most of their recitals and other public performances - a tradition indebted to Clara Schumann and Franz Liszt, dating back to the 1800s. Although "memorized performances were considered to be in bad taste and ostentatious even towards the end of the nineteenth century,"1 they have become standard practice and, indeed, necessary.

Memorization is a process that is done consciously and with a specific intention, ${ }^{2}$ a process that can be more challenging to some pianists than others. In fact, all learning processes are really memory processes. ${ }^{3}$ The process of memorization is the result of acquiring musical knowledge and skills that constitute the total musicianship of memorization. Because there are many factors that may affect memorization, including prior experience in memorization, prior musical background, length of composition, and kind of repertoire, to name a few, it is important to examine thoroughly the nature of the stimulus involved in the music learning process. ${ }^{4}$

Scholars have done much research on the memorization of piano music from the stages involved in the memorization process to minimizing memory slips and recovering from memory

\footnotetext{
${ }^{1}$ Aaron Williamon, "Memorizing Music" in Musical Performance: A Guide to Understanding, ed. John Rink (Cambridge: Cambridge University Press, 2002), 113.

${ }^{2}$ Stephen Weber, "Memory: Beyond Remembering," Piano Pedagogy Forum v. 2 no, 1, 1 January 1999 [journal online]; available from http://www.music.sc.edu/ea/keyboard/PPF/2.1/2.1.PPFp.html; Internet; accessed 9 March 2009.

${ }^{3}$ Roger Chaffin and Gabriela Imreh, "Understanding and Developing Musical Memory: The Views of a Concert Pianist and a Cognitive Psychologist," American Music Teacher 46 no. 3, December/January 1996/97, 24.

4 Eunice Rickey, "An Investigation to Observe the Effects of Learning Style on Memorization Approaches Used by University Group Piano Students When Memorizing Piano Literature.” (D.A. diss., Ball State University, 2004), 23.
} 
lapses during a performance. Numerous books and articles have been published, along with information on websites and video materials, presenting various ways to approach memorization from both musical and psychological points of view. This research project provides reviews of resources for pianists, performers, teachers and students, striving to deepen their knowledge of memorization techniques and explore different methods of memorizing piano music and for scholars pursuing further research on this important topic. Readers will find that there are common traits of memorization that scholars have agreed upon throughout the century, such as four elements of memory (aural, visual, kinesthetic, and analytical), as well as a rise of interest and recent development in the research for the past decade, including in such areas as expert memory and piano performance, and the effect of sleep and time on musical memory.

\section{Limitations of Study}

This research project incorporates resources from the 1890s through the first decade of the $21^{\text {st }}$ century. Readers will find resources that discuss the topic from the musical and psychological standpoints, but not a scientific approach to brain and memorization. Resources include books, journal articles, and theses/dissertations that are written in English. Online resources or websites are not included in this project due to the inconsistency and unreliability of their nature. Resources that discuss single-line instrumental music memorization are also excluded from this project.

\section{Method of Research}

Among the search engines explored are RILM Abstracts of Musical Literature, Dissertation Abstracts Online (Dissertations and theses from institutions in North America and 
Europe), ECO (an OCLC collection of scholarly journals), ArticleFirst (OCLC index of articles from the contents pages of journals), Ebooks (OCLC catalog of online electronic books available through libraries worldwide), Music Index Online, JSTOR, the West Virginia University MountainLynx catalog, and the Library of Congress catalog. To date, the author has found eighteen books, forty-five journal articles, and thirteen thesis/dissertations that make significant contributions to this project.

Following this introduction, separate chapters are used for books, articles and theses/dissertations, along with a final chapter of summary and conclusions. Sources are catalogued based on the year they were written, from the earliest to the most recent. The standard format of bibliographical entries according to Turabian's A Manual for Writers of Research Papers, Theses, and Dissertation has been used. Each entry consists of bibliographic information (author, title, publication name, volume, year, and page number) and a summary annotation including general information about the types of questions or issues addressed by the work. A biography of the author, when available, is also included with each entry. The last chapter focuses on personal observations and conclusions on how memorization techniques of piano music have developed from the $20^{\text {th }}$ century to today. 


\section{CHAPTER II}

\section{Annotated Bibliography - Books}

1. Shinn, Frederick G. Musical Memory and Its Cultivation: Also an Investigation into the Forms of Memory Employed in Pianoforte Playing, and a Theory as to the Relative Extent of the Employment of Such Forms. London: Augener Ltd., 1898.

A discussion of memory and its connection with music and musical performance. The first part of the book discusses the various forms of memory employed in piano playing (muscular memory, visual memory, and intellectual memory) and the relative extent of the application of the various forms by different individuals. The second portion of the book examines the cultivation of musical memory such as general conditions favorable to memorizing, the value of early training, principles which should guide us in the selection of pieces, how to study a piece intelligently, rehearsing from memory, and memory performance in examinations. The last chapter entitled "The Memories of Musicians" is a collection of evidences of remarkable powers of memory by famous musicians: Mozart, Mendelssohn, Ferdinand Hiller, Hans von Bülow, Sir Charles Hallé, Rubinstein, Dr. Hans Richter, Sir Frederick Ouseley, and Sir Walter Parratt. Musical examples include compositions by Beethoven, Brahms, Chopin, Mendelssohn, Schubert, Schumann, and Weber.

[Frederick G. Shinn (1867-1950) was Mus. Doc., Dunelm, Associate of the Royal College of Music, fellow of the Royal College of Organists.]

2. Kenyon, C. Fred. How to Memorise Music: with Numerous Musical Examples. London: W. Reeves, 1904.

One of the earliest comprehensive guides that introduces the concepts of the Faculty of Analysis, the Faculty of Touch, the Faculty of Hearing, the Faculty of Sight, and the Faculty of Emotion in assisting one to memorize piano music. The Faculty of Analysis is knowledge of harmony; the Faculty of Touch is a mechanical faculty and needs other well developed faculties to support it; the Faculty of Hearing involves training the ear to memorize music; the Faculty of Sight (photographic memory) is one's ability to see the printed page while performing and is rare. The author insists on the necessity of the Faculty of Emotion of all pieces that the student wishes to memorize. Musical examples include sonatas by Beethoven, etudes by Chopin, and Mendelssohn's Songs Without Words.

[No biography was found.]

3. Goodrich, A. J. Guide to Memorizing Music. New York: John Church Co., 1906.

An approach to memorizing piano music by apprehending and executing musical designs, rather than memorizing by rote. Topics covered are diatonic melodic sequences, harmonic cadences, various forms of complete and perfect cadences, themes and designs formed upon 
cadence harmonies, non-chord tones (suspension, appoggiatura, passing notes, gruppetti, anschlag), chromatic and chord sequences, canonic imitations, form, miscellaneous examples from Beethoven, and examination of the structure of a few compositions written since the death of Beethoven and Schubert.

[A. J. Goodrich was the author of such works as Complete Music Analysis, Analytical Harmony, Synthetic Counterpoint, Theory of Interpretation, Music as a Language, and The Art of Song.]

4. Matthay, Tobias. On Memorizing and Playing From Memory; and on the Laws of Practice Generally. London: Oxford University Press, 1972 (c1926).

A thorough discussion on the processes applied during the preparation of a performance and during an actual performance. The author proposes that memorizing requires some form of connection, progression, or sequence of thought. Various forms of memory available in playing include: 1) The Musical Memory - melodic, harmonic, rhythmical, and modal memory, 2) The Visual Memory - eye-memory of the page and eye-memory of the keyboard progressions and combinations, and 3) The Muscular Memory - the sense of place on the keyboard and the sense of key-motion or key-resistance. Musical examples include Chopin's B minor Scherzo, Beethoven's Piano Sonata Op. 110 (I), and Schubert's Impromptu in E-flat.

[Tobias Matthay (1858-1945) was an English pianist, teacher, and composer. He taught piano at the Royal Academy of Music in London, England for over fifty years. Matthay's revolutionary concepts about the displacement of tension and his attention to natural musical laws attracted considerable attention. In 1905 he opened the Tobias Matthay Piano School while continuing at the Royal Academy. The playing of Myra Hess, Irene Scharrer, Clifford Curzon, Moura Lympany and others trained by him soon established his position as one of the greatest pedagogues of all time. ${ }^{5}$ ]

\section{Hoffzimmer, Ernest. The Musical Memory. Bloomington: Indiana University, 1931.}

A lecture given in the School of Music of Indiana University on different types of musical memory. The ear, the eye, the touch, or the senses of hearing, seeing, and feeling, are each presented as important in learning music. The author gives the first place to the ear and the whole ear complex: the receiving ear, the memory of the ear, and the recognizing and recreating in the mind. The second sense is the eye. One not only has to read music with it, but one has to observe their instrumental behavior or technique. The third place is given to the sense of physical feeling, the feeling of grips and passages, of tensions and relaxations, on the instrument. In addition to what comes from the senses, there is the architecture of music, the form, which comes from intelligent study of literature, theory, counterpoint, and composition. The author also points out that there are living energies beyond a perfect memory. They are the powers of personality, imagination, and suggestion.

[Ernest Hoffzimmer taught at the Stern Conservatory in Berlin and at the Dusseldorf Conservatory. While teaching in Europe, he also earned an enviable reputation as a concert pianist, presenting the premier performance of works by Swedish composer Ruben Liljefors and

\footnotetext{
${ }^{5}$ http://www.matthay.org/ [Accessed 15 April 2011].
} 
Finnish composer Selim Palmgren. Hoffzimmer came to Indiana University in 1927 and quickly established himself as one of the Midwest's outstanding master teachers of keyboard technique. After his retirement, he moved to California where he became head of the piano department at Southern California School of Music in Los Angeles. $\left.{ }^{6}\right]$

6. Rubin-Rabson, Grace. The Influence of Analytical Pre-Study in Memorizing Piano Music. New York: Archives of Psychology, 1937.

A study that compares the efficiency of two procedures in memorizing piano music. One procedure includes the study and analysis of the musical material before continuing the learning at the keyboard; the other omits this analytical study and confines the entire learning to the keyboard. Four methods were compared for their relative economy. Two of the methods involved the use of study and analysis before learning. In one the studying was done with the aid of a prepared analysis, in the other the analysis was prepared by the subject. The third method included no study previous to the keyboard learning. The fourth method was designed to test the value of familiarity with the musical material from hearing it before learning it by any of the other methods. The efficiency of each method was evaluated by relearning time or relearning repetitions which occurred three weeks after the original learning. Study periods were omitted and all learning was limited to the keyboard.

Data analysis showed that the method which included the formulation of an analysis by the subject proved superior to the method without such analysis. Even inexpert and inexperienced analysis is much better than none at all. Preliminary hearing of the musical material before learning showed no advantage in relearning over doing without this preliminary hearing. The author also stated that no relationship exists between piano experience and learning. Experience in playing does not imply that memorizing of new material will be quickened in direct ratio to the amount of such experience.

[No biography was found.]

7. Cooke, James Francis. How to Memorize Music. Philadelphia: T. Presser Co., 1948.

A detailed presentation of practical steps in memorizing as well as employment of hearing, sight, and the kinesthetic sense. A Symposium Upon Memorizing is a chapter devoted to contemporary pianists and their methods of memorizing, including Harold Bauer, Maurice Dumesnil, Rudolph Ganz, Heinrich Gebhard, Percy Grainger, Howard Hanson, Josef Hofmann, Edwin Hughes, Ernest Hutcheson, Guy Maier, Isidor Philipp, Moriz Rosenthal, Olga SamaroffStokowski, Silvio Scionti, Victor Seroff, Reginald Stewart, Sigismond Stojowski, and John Finley Williamson.

[James Francis Cooke (1875-1960) was an editor-in-chief for The Etude, a U. S. magazine dedicated to music, from 1909 to 1946.]

\footnotetext{
${ }^{6} \mathrm{http} / / /$ music.indiana.edu/giving/scholarships/scholarships-hoffzimmer.shtml [Accessed 3 October 2011].
} 
8. Rubinstein, Beryl. The Pianist's Approach to Sight-Reading and Memorizing. New York: C. Fischer, 1950.

An elaborate explanation on how memorization is assisted mainly by a recognition and understanding of musical elements. The author presents four component parts of memory: aural memory, visual memory, tactile memory, and analytical memory. Aural memory is basic in learning to play a piece of music from memory and controls the functioning of the other memories. Visual memory serves as a guide to the other memories. Tactile memory requires consistency in using the same fingering every time a piece is practiced or played. Analytical memory involves the understanding of musical structure, chain of events, as well as tonal philosophy.

[Beryl Rubinstein (1898-1952) was a piano virtuoso, music educator, and composer. $\mathrm{He}$ taught at the Cleveland Institute of Music in Cleveland, Ohio, from 1921 until his death, serving as director of the school for the last two decades of his life. $\left.{ }^{7}\right]$

9. Ahrens, Cora B., and G. D. Atkinson. "Memorizing." In For All Piano Teachers, 80-83. Oakville, Ontario: The Frederick Harris Music, c1954.

An overview of aural memory, visual memory, tactual memory, kinesthetic memory, and analytical memory. This chapter also discusses relevant factors that affect performing from memory: silent study, when to memorize, practice performing, nervousness, correct practice, deep breathing, and self control.

[Cora B. Ahrens (1891-1964) was the author of such works as Ear Training, Daily Exercise in Sight Playing, Rudiments of Music, and Mother Goose of Rhymes in Rhythm.]

[G. D. Atkinson (1878-1964) was a lecturer in Psychology and Pedagogy of the School of Music and Faculty of Music of the Royal Conservatory of Music, University of Toronto.]

10. D'Abreu, Gerald. "Memory." In Playing the Piano with Confidence: An Analysis of Technique, Interpretation, Memory, and Performance, 89-102. New York: St. Martin's Press, 1965.

A discussion of partial memory, muscular memory, aural memory, photographic memory (or 'keyboard memory'), concentration, analysis, memorizing melodically, memorizing parts, memorizing harmonically, memorizing twentieth-century music, memorizing away from the keyboard, memorizing before practicing, memorizing in sections, memorizing as a whole, growth of memory, co-ordination of all types of memory, hypnotic effect of fear, and memory made safe. Musical examples include J. S. Bach's Fugue in B-flat from the Well-Tempered Clavier, Book I, Chopin's Prelude in C op. 28 no. 1, and Bartok's Improvisation op. 20 no. 7.

[No biography was found.]

\footnotetext{
${ }^{7}$ http://www.georgiaencyclopedia.org/nge/Article.jsp?id=h-2698 [Accessed 20 April 2011].
} 
11. Sándor, György. "Memorization." In On Piano Playing: Motion, Sound, and Expression. New York: Schirmer Books, 1981.

A single chapter from the book on when to memorize music and four memory components. The author recommends to concentrate on memorization only when the material is ready to be stored - that is, when most of the technical and musical problems have been cleared. Four ingredients share in the process of memorization: (1) visual memory, (2) acoustic or aural memory, (3) motoric or kinetic memory, and (4) intellectual or analytical memory. The author recommends identifying the weakest of the four ingredients, working on it first, and then following through with the others.

[György Sándor (1912-2005) was an internationally respected pianist and piano teacher, especially known for his recordings of music of Bartók and Prokofiev. He made his concert debut in Budapest in 1930 and toured widely through Europe until 1939. In that year Sándor left for the United States. He became a naturalized citizen of that country in 1943. In 1956 he joined the faculty of Southern Methodist University in Dallas, TX, remaining there until 1961. In that year he moved to the University of Michigan, Ann Arbor, as director of graduate studies in piano. In 1982 he left Ann Arbor to join the piano faculty of the Juilliard School of Music in New York. $\left.{ }^{8}\right]$

12. Reubart, Dale. Anxiety and Musical Performance (On Playing the Piano from Memory). New York: Da Capo Press, 1985.

A detailed discussion on many elements of performance anxiety and the array of solutions to counter that syndrome. Chapters Three, Four, and Five focus on different aspects of performing from memory such as consciousness in practice, consciousness in performance, consciousness in listening to the music, the role of the visual system in playing from memory, pitch perception and improvised playing, establishing auditory and haptic memory, "forgetting the notes" and losing control, as well as solving musical problems.

[Dale Reubart taught piano at the University of Southern California (1956-1960), at Western Washington State College (1960-1963), and at the University of British Columbia (1963-1986). Specializing in 19th- and 20th-century piano music, Reubart has performed as soloist, chamber player, accompanist, and lecture-recitalist in several North American centers and has written articles on performance practices. In 1979, he began research into performance anxiety and in 1983 began to lecture on the subject widely in Canada, the USA, and Great Britain, leading many practical workshops for musicians suffering from stage fright. $\left.{ }^{9}\right]$

13. Shockley, Rebecca Payne. Mapping Music for Faster Learning and Secure Memory: A Guide for Piano Teachers and Students. Madison: A-R Editions, Inc., 1997.

A tool to help pianists develop their own approach to mapping a piece of music. Mapping is a simple strategy for learning and memorizing music more efficiently. The technique used is

\footnotetext{
${ }^{8} \mathrm{http} / / / \mathrm{www}$. allmusic.com/artist/gyrgy-sndor-q50612/biography [Accessed 7 October 2011].

${ }^{9} \mathrm{http}: / /$ www.thecanadianencyclopedia.com/index.cfm?PgNm=TCE\&Params=U1ARTU0002961 [Accessed 9 April 2011.]
} 
diagramming the main features of a piece and using this diagram as a "map" for learning the music. Over 50 musical excerpts from elementary to advanced level, along with practice ideas and samples of mapping techniques, are included. The author encourages readers to be creative with their own ways of mapping. Some of the musical examples are Kabalevsky: A Little Joke, op. 39 no. 6, Satie: Gymnopedie no. 3, C. P. E. Bach: Solfeggieto, and Schubert: Impromptu in A-flat minor, op. 90 no. 4 (Trio).

[Rebecca Shockley is Professor of Piano Pedagogy and Coordinator of Class Piano at the University of Minnesota. She has given presentations on music learning at colleges, universities, and for music teacher organizations across the U.S. and in England, Canada, Taiwan, China and Korea. An active member of Music Teachers National Association, Shockley chaired the Pedagogy Saturday Committee for two years and previously served on the National Convention Program Committee. For twelve years she also chaired the Committee on Learning Theory for the National Conference on Piano Pedagogy. She has given clinics for Frederick Harris and the Lorenz Corporation, and she served on the Advisory Board for Piano Discoveries, a recent piano method published by Lorenz. Mapping Music was also published in a Korean translation by Hanyang University Press in 2002. ${ }^{10}$ ]

14. Aiello, Rita and Aaron Williamon. "Memory." In The Science and Psychology of Music Performance: Creative Strategies for Teaching and Learning, Richard Parncutt and Gary E. McPherson, eds. Oxford; New York: Oxford University Press, 2002.

An analysis of existing literature on how to memorize music. The authors suggest that general theories of expert memory can help in understanding how expert musicians memorize music. Musical memory involves aural, visual, and kinesthetic information. The skill of the performer and the style and difficulty of the music to be memorized determine the strategies used. A study of music theory and analysis is a tool to enhance the performer's ability to memorize. According to the authors, learning to improvise in the style of the music could also be beneficial.

[Rita Aiello has served on the faculties of The Juilliard School, The Manhattan School of Music, and The City University of New York. She has also been a visiting professor at Universita' Degli Studi di Roma "La Sapienza", and a visiting scholar in this department. Her research addresses mainly the perceptual and the cognitive processes that we apply when listening to music, and the relationship between the mental representation and the emotional import of music. ${ }^{11}$ ]

[Aaron Williamon is Professor of Performance Science at the Royal College of Music. His research focuses on skilled performance and applied scientific and health-related initiatives that inform music learning and teaching. Aaron is a fellow of the RSA and the UK's Higher Education Academy and has been elected an Honorary Member of the RCM. In addition, he has performed as a trumpeter in chamber and symphony orchestras, brass bands, and brass quintets in both Europe and North America. $\left.{ }^{12}\right]$

\footnotetext{
${ }^{10} \mathrm{https}: / /$ music.umn.edu/people/faculty-staff/profile?UID=shock001 [5 April 2011].

${ }^{11} \mathrm{http}: / /$ www.psych.nyu.edu/aiello/ [Accessed 20 February 2011].

$12 \mathrm{http} / / / \mathrm{rcm}$.academia.edu/AaronWilliamon [Accessed 20 February 2011].
} 
15. Chaffin, Roger, Gabriela Imreh, and Mary Crawford. Practicing Perfection: Memory and Piano Performance. Mahwah: Lawrence Erlbaum Associates Inc., 2002.

A perspective on memorization from a concert pianist, a cognitive psychologist, and a social psychologist. The pianist video-taped her practice as she learned the third movement, Presto, of the Italian Concerto for a CD of works by J. S. Bach (Imreh, 1996). A CD accompanies this book containing the performance that marked the end result of the learning process. Collections of interviews with great pianists regarding their own preparations for performance are included in chapter three. Among them are Martha Argerich, Claudio Arrau, Vladimir Ashkenazy, Harold Bauer, Jorge Bolet, Alfred Brendel, Misha Dichter, Rudolf Firkusny, Leon Fleisher, Percy Grainger, Josef Hofmann, Stephen Hough, Edwin Hughes, Murray Perahia, Artur Rubinstein, Olga Samoroff, Rudolf Serkin, and Andre Watts.

[Roger Chaffin is a teacher and researcher with the Department of Psychology at the University of Connecticut. His research interests have included the differences between linguistic and factual knowledge the involvement of semantic processes in word learning and definition and eye movements during the learning of a new word. Chaffin's largest and most recent body of research has concentrated on music performance.]

[Gabriela Imreh is a classically trained professional pianist. In addition to her performing and recording activities Imreh has served on the faculty at several universities, including a 2003 appointment as Guest Professor at the University of Connecticut.]

[ Mary Crawford is Professor of Psychology at the University of Connecticut. Her research interests primarily involve gender and communication, feminist research methods, as well as gender and cognition.]

16. Williamon, Aaron. "Memorising Music." In Musical Performance: A Guide to Understanding, ed. John Rink, 113-128. Cambridge; New York: Cambridge University Press, 2002.

A summary of studies which have examined musical memory systematically. Williamon covers subject matters such as: exploring why musicians perform from memory and exploring how musicians perform from memory (methods of memorizing music, interviews with musicians, and the principles of expert memory). The author suggests that the extent to which certain analytical strategies are the most effective and efficient need to be addressed by subsequent research.

[Aaron Williamon is Professor of Performance Science at the Royal College of Music. His research focuses on skilled performance and applied scientific and health-related initiatives that inform music learning and teaching. Aaron is a fellow of the RSA and the UK's Higher Education Academy and has been elected an Honorary Member of the RCM. In addition, he has performed as a trumpeter in chamber and symphony orchestras, brass bands, and brass quintets in both Europe and North America. ${ }^{13}$ ]

${ }^{13} \mathrm{http} / / / \mathrm{rcm}$.academia.edu/AaronWilliamon [Accessed 20 February 2011]. 
17. Ginsborg, Jane. "Strategies for Memorizing Music." In Musical Excellence: Strategies and Techniques to Enhance Performance, ed. Aaron Williamon, 123-141. Oxford: Oxford University Press, 2004.

A review of memorization strategies that are based on a critique of existing observational and empirical research, accomplished within the context of Western classical music. This chapter begins with an introduction on basic principles of human memory, followed by an exploration of musical memory specifically and a selection of strategies commonly used by musicians. The chapter closes with a brief discussion of how individual differences in learning styles may impact one's capacity to memorize. An extensive list of references is included at the end of the chapter.

[Jane Ginsborg is Associate Dean of Research and Enterprise \& Director, Centre for Music Performance Research at the Royal Northern College of Music in Manchester, United Kingdom. Her principal research interests are in singing, and in expert musicians' preparation for performance and long-term recall of music. Current and recent investigations include interactive performance for musicians with hearing impairments, the teaching and learning of small group performance, the roles of gesture and talk in duo rehearsal, dancers' long-term recall for movement with and without music, musicians' career transitions, and musicians' health. ${ }^{14}$ ]

18. Gordon, Stewart. "Techniques to Develop Secure Memorization." In Mastering the Art of Performance: A Primer for Musicians, 81-89. New York: Oxford University Press, 2006.

A discussion of four characteristics that are present in memorizing music for performance: 1) Complexity of material, 2) Anticipated level of precision, 3) Time issues, and 4) Anxiety. The author suggests the complexity of material can be solved through the use of specific techniques: analyze structural organization, think about the conceptual meaning behind the material, break the material down into small units, and construct mnemonic references as one memorizes. Setting up start-up points will build a safety net, should anxiety cause a blank out during a performance.

[Stewart Gordon is a musician, teacher, writer, editor, composer, and impresario. $\mathrm{He}$ holds the position of Professor of Keyboard Studies at the Thornton School of Music of the University of Southern California in Los Angeles. As a performing pianist, he has played concerts throughout the world and recorded extensively, both to critical acclaim. As a teacher and author he has produced textbooks, essays, videotapes, and editions. As a composer, his musical theater works have been produced from coast to coast, and as an impresario, he has directed music festival and competitions over the past decades in New York, Washington, and Savannah. $\left.{ }^{15}\right]$

\footnotetext{
${ }^{14} \mathrm{http} / / /$ www.rncm.ac.uk/meet-our-staff-mainmenu-51.html?view=item\&catid=431\%3Aresearch-aenterprise \&id $=544 \% 3$ Adr-jane-ginsborg [Accessed 10 October 2011].

${ }^{15} \mathrm{http} / / /$ stewartgordon.com/ [Accessed 20 April 2011].
} 


\section{CHAPTER III}

\section{Annotated Bibliography - Journal Articles}

1. Hughes, Edwin. "Musical Memory in Piano Playing and Piano Study." Musical Quarterly 1 (1915): 592-603.

One of the earliest sources on musical memory. The author suggests concentration is the one most necessary factor in memorizing music. One's physical condition, such as a sleepiness or sickness, may very well affect one's ability to memorize and reproduce from memory. Three methods of memorizing piano music are discussed: by ear, by visual memory, either of the notes on the printed page or the notes on the keyboard, and by finger memory or reflex action. A valuable supplement to intelligent memorizing is having knowledge of harmony and musical form, as well as of counterpoint and fugue.

[Edwin Hughes was an American pianist and teacher. He taught at the Ganapol School of Musical Art in Detroit, the Volpe Institute of Music in New York, and the Institute of Musical Art in New York. From 1920 to 1926 he was special editor of piano music for G. Schirmer, Inc. He toured widely in the USA and Europe after the close of World War I, performed duo-recitals with his wife, the pianist Jewel Bethany Hughes, and also gave master-classes. ${ }^{16}$ ]

2. Rubin-Rabson, Grace. "Studies in the Psychology of Memorizing Piano Music: I. A Comparison of the Unilateral and the Coordinated Approaches." Journal of Educational Psychology XXX (1939): 321-345.

A study that compared the security of learning achieved by an approach in which either hand was memorized before coordination, with an approach in which the learning was coordinated from the beginning. The four methods presented provide combinations of Interrupted and Uninterrupted study periods, Coordinated and Separate hand practicing. Two learnings were accomplished at each session with a short rest period between them. The relearnings were done two weeks from the date of the learning, and followed the same experimental pattern as the learnings except that the preliminary study period was omitted and the relearning was done by the coordinated approach.

Four complete eight measure fragments were chosen for their simplicity, attractiveness, and unfamiliarity. Thirty-six subjects from the music schools of New York City participated in this study. All of them were serious music students or professional musicians. The author concludes that unilateral trials preliminary to coordinated trials produce greater stability and clarity in the learning of piano material.

[No biography was found.]

\footnotetext{
${ }^{16} \mathrm{http} / / /$ www.bach-cantatas.com/Lib/Hughes-Edwin.htm [Accessed 26 March 2011].
} 
3. Rubin-Rabson, Grace. "Studies in the Psychology of Memorizing Piano Music: II. A Comparison of Massed and Distributed Learning." Journal of Educational Psychology XXXI (1940): 270-284.

A study designed to retest the long-established superiority of distributed over massed practice. Three methods of practice were contrasted as follows: (A) massed learning, (B) distributed learning - two practice periods in one day about one hour part, and (C) distributed learning - two practice periods in two days about twenty-four hours apart. For all three methods, the standard completed learning was one smooth memorized performance by the right hand alone, one by the left hand alone, and one smooth coordinated performance. Relearning was accomplished exactly two weeks from the date of the learning. This involved no preliminary study and was done by the coordinated approach.

Nine eight-measure periods were adapted from compositions covering a wide range of era and style. The nine subjects, one man and eight women, were all experienced pianists. The number of learning trials required by the three methods showed no differences, though the massed-trial study produced a greater degree of over-learning. Based on the analysis of all the variables in the relearning situation, in this instance, distributed practice should be recommended for less able learners. For the more able, either approach is equally productive.

[No biography was found.]

4. Rubin-Rabson, Grace. "Studies in the Psychology of Memorizing Piano Music: III. A Comparison of the Whole and the Part Approach." Journal of Educational Psychology XXXI (1940): 460-476.

A study intended to provide experimental support for the general assumption that whole learning is in some way intrinsically superior to part learning. The whole-part problem here is reduced to its simplest form: an eight-measure period. Nine units of approximately eight measures each were adapted from various styles of unfamiliar piano material and learned either as a whole, in two phrases, or in four small figures. Subjects were nine adult skillful pianists who repeated the experiment three times, memorizing three compositions by each of the three methods. Each keyboard memorizing was preceded by an analytical study period of fixed length. The relearning to measure retention took place two weeks later, without study period or separate hand practice. The subject also transcribed the score on music paper after each memorized relearning to further check on the accuracy of the retention.

The author suggests that no superiority can be found in any of the three approaches, nor is retention in any way affected by having first learned the whole in smaller parts. The standard deviation of the group decreases progressively as the units of learning are smaller. This suggests that a group of music students of diverse capabilities could be advised to work in as small units as they individually find satisfactory. On the other hand, the larger standard deviation for the whole approach indicated that the ability to work comfortably with larger unites is specific to the more capable subjects. Furthermore, the musical value of thinking in larger units, apart from any consideration of learning efficiency, recommends that the length of the unit be increased as the student grows in capacity.

[No biography was found.] 
5. Rubin-Rabson, Grace. "Studies in the Psychology of Memorizing Piano Music: IV. The Effect of Incentive." Journal of Educational Psychology XXXII (1941): 45-54.

An experiment designed to examine the effect of incentive on the learning "plateaus" such as fatigue, lack of interest and attention, and relaxation of the "will to do." Three kinds of learning were compared: free or unmotivated except for the factors already existing in the situation; spurred by a verbal exhortation to work with maximum speed and intensity; urged by the cash incentive in proportion to speed. Nine subjects of advanced musical accomplishment repeated the entire experiment three times using different learning materials each time. The nine unfamiliar experimental compositions ranged from eight to fourteen measures in length and were adapted from the piano works of relatively obscure $18^{\text {th }}$ century composers.

The author concluded that for each individual a minimum number of trials is required to bring the learning of a complicated skill to a given point of perfection and that this number can not be reduced by added incentives. Interest in the work itself, pride in personal production and efficient learning techniques are at least as effective as any irrelevant incentives that can be applied externally.

[No biography was found.]

6. Rubin-Rabson, Grace. "Studies in the Psychology of Memorizing Piano Music: V. A Comparison of Pre-Study Periods of Varied Length." Journal of Educational Psychology XXXII (1941): 101-112.

A study on how far silent study and analysis shall be carried before keyboard practice. Nine musical examples of unfamiliar $18^{\text {th }}$ century piano music were studied for three, six, and nine minutes before continuing the memorizing to perfect performance at the keyboard. At the end of the study period, the material was transcribed from memory as a check on the stage of the learning. Two weeks later it was relearned to measure the relative retention values of the several amounts of preliminary study. Nine adults, all competent musicians and skillful pianists, each performed the experiment three times, so that twenty-seven learning trials resulted from each method, or eighty-one learning trials in all.

The author suggests, as indicated by transcriptions of the memorized material, the medium study period produced one hundred percent learning and the longest period allowed time for a considerable amount of over learning. Gauged by the keyboard trials, the longer study periods proved economical but not in proportion to the time invested; gauged by the amount of retention over a period of two weeks, there were no economies in any one of the three varied lengths.

[No biography was found.]

7. Rubin-Rabson, Grace. "Studies in the Psychology of Memorizing Piano Music: VI. A Comparison of Two Forms of Mental Rehearsal and Keyboard Overlearning." Journal of Educational Psychology XXXII (1941): 593-602.

An experiment that attempts to evaluate a further period of study or mental rehearsal situated at points in the learning when some keyboard learning has already been accomplished. 
Three procedures were compared, all of which incorporated a five-minute period of analysis preliminary to any keyboard trials. The first introduced a four-minute period of mental rehearsal or "imaginary" practice after five keyboard trials or mid-way in the learning, then continued the keyboard trials to reach the criterion of perfect memorized performance. The second carried the keyboard trials to the criterion, and then added four minutes of mental rehearsal. The third, like the second, reached the keyboard criterion, and then added extra keyboard trials for four minutes. Exactly two weeks later the relearning was done without study periods to measure the relative retention offered by the three learning methods. A second relearning occurred seven months after the learning to estimate the residual benefits.

Subjects participated in the study were nine adult skillful pianists, most of them piano teachers. Nine short but complete musical periods ranging from five to ten measures in length were adapted from unfamiliar piano materials by Zipoli, Pasquini, Galuppi, Frey, Dohnanyi, Gal and Toch. The mid-way period of mental rehearsal or "imaginary" practice proved reliably superior to the other time distribution. The four minutes of mental rehearsal placed after the learning is, apparently, an inferior procedure. It not only required more keyboard trials, but produced less retention than either of the other methods. In the second relearning after seven months these differences disappeared.

[No biography was found.]

8. Rubin-Rabson, Grace. "Studies in the Psychology of Memorizing Piano Music: VII. A Comparison of Three Degrees of Overlearning." Journal of Educational Psychology XXXII (1941): 688-696.

An experiment that evaluates proportional degrees of over learning past the criterion of smooth memorized performance by adding fifty, one hundred, and two hundred per cent of the learning trials to the finished product. After two weeks and again after seven months the relearning took place without preliminary study. All keyboard trials were done by massed learning, by the "whole" approach and without the benefit of separate-hand learning.

Data analysis shows that there are almost no differences in the means after two weeks and after seven months. This supports the assumption that effective learning is insured by an emphasis on pre-keyboard analysis plus an immediate memorizing under the intensive conditions of the experimental situation. It might be recommended that the most economical learning procedure is one which carries an intensive logical learning to the criterion of smooth memorized performance and saves the extra trials for subsequent practice periods to restore the learning to this same level.

[No biography was found.]

9. O'Brien, Cyril C. "Part and Whole Methods in the Memorization of Music." Journal of Educational Psychology 31 (1943): 552-560.

Six experiments conducted by comparing part and whole methods of memorizing music after an isolation of factors comprising composite memory. Four graduate students of the Maritime Academy of Music, Halifax, N. S., Canada, acted as subjects. Data analysis demonstrated that music memorization involving auditory, visual, and tactile abilities, when the 
music is well within the range of the technique of the subjects, the part method of memorizing is more economical.

[Cyril Cornelius O'Brien established the first courses in the psychology of music in Canada in 1935 by at the Maritime Academy of Music. As head of the academy's department of psychology until 1947, O'Brien taught courses in the psychology of music, administered tests of musical talent, and wrote articles on music aptitude tests (1935), tonal memory (1943, 1953, 1958), and tone color discrimination (1945). $\left.{ }^{17}\right]$

10. Schweishmeir, Waldemar. "How Good is Your Musical Memory?" Etude 73 (February 1955): 20-50.

An informative discussion of musical memory and different aspects that affect it. The author suggests the capacity of memory decreases with progressive years. The musical pieces learned three decades ago tend to stay better in one's memory when aging, than those learned only recently. In addition to aging, the author suggests some diseases and physical disorders are connected with decreasing memory, such as anemia, adenoids, habitual nose bleeding, disorders of the blood vessels, and overactive thyroids (goiter), chronic constipation, etc. Fatigue also plays an important part in loss of memory. On the other hand, sleep will restore the faculty of remembering. Lastly, increased use of memory will make it stronger. Good and enduring results are obtainable only through a series of small but continuous daily effort.

[No biography was found.]

\section{Bryant, Celia Mae. "Memorizing: A Science.” Clavier 2 (October 1963): 20-25.}

An article on how to memorize through the principles involved in the understanding of music theory. The author suggests successful memorizing will be affected by three conditions: interest, mental capacity, and experience. The first part of the article discusses four aids that will establish desirable associations for memorizing: analytical, aural, tactile, and visual. The best memory work includes all four aids, assuming that technical difficulties are adequate to meet the requirements of the composition. The second part of the article explains the procedure of memorizing, rechecking the knowledge after a piece is memorized, recitals, and nervousness. The author uses Bach's Musette in D major as an illustration on how to memorize.

[Celia Mae Bryant died August 4, 1999. For many years she was a regular contributor to Clavier, providing insightful articles on piano pedagogy from their very first issue in March 1963. Many of her articles on master lessons were recorded in Braille by the Library of Congress. She was a past president of the Music Teachers National Association and taught at the University of Oklahoma School of Music as well as at Interlochen.]

\footnotetext{
${ }^{17} \mathrm{http} / / /$ www.thecanadianencyclopedia.com/index.cfm?PgNm=TCE\&Params=U1ARTU0002884 [Accessed 2 June 2011].
} 
12. Kohler, Jean Charles. “Some Ideas on Memory.” Clavier 5 (May/June 1966): 45-49.

An article that promotes the superiority of the analytical approach to memorizing music in terms of speed of memory and in terms of reliability. The author explains that there are two principles of the analytical approach: the "type chord" approach and "playing by ear." A chart of chord types built on $\mathrm{C}$ is enclosed to help students understand the type chord system. The advantage of this system is that it is practical regardless of frequent key and chordal changes. Playing by ear involves improvisation to some extent with a given chord pattern so that students can quickly see and use a chordal approach to memory. Musical examples include Chopin's Tarantelle, Op. 48, and Rachmaninoff's Piano Concerto No. 1 in F-sharp minor.

[No biography was found.]

13. Tallarico, P. Thomas. "A Musical Investigation of the Kamin Effect." Journal of Research in Music Education V. XXI, no. 2 (Summer 1973): 153-161.

A study that was constructed to further investigate the results of Kamin's studies in relation to the amount of retention or number of correct responses. In 1957 Leon J. Kamin began a study of laboratory animals that were trained to avoid punishment by moving from one end of a shuttle box apparatus to the other. The number of correct responses or avoidances recorded during the relearning trials provided a measure of retention. Kamin's data revealed that the amount of retention or number of correct responses declined significantly when the intervals between sets of trials were from zero to one hour, but the number of correct responses increased significantly when intervals were from one hour to nineteen days.

Forty undergraduate students with prior musical training served as subjects of Tallarico's study. A two-part test was constructed that included musical stimuli. The author suggests that the evidence shows a phenomenon similar to what has been described as the Kamin effect occurs when human subjects are presented auditory musical stimuli without punishment. In both experiments, the number of correct responses at first decreased with time and followed by an increase in the number of correct responses made by subsequent groups. However, further investigations are needed to conclude that the outcome of this study substantiates the three-phase concept of memory (a short-term memory, an intermediate-term memory, and a long-term memory). University.]

[P. Thomas Tallarico was Professor and Chair Emeritus at Bowling Green State

14. Schmied, Al. "The Importance of Developing Kinesthetic (Finger) Memory in Piano Performance." American Music Teacher 23, no. 5 (1974): 10-12.

The author presents his strong conviction that kinesthetic or tactile memory, reinforced by the tonal memory, plays the most essential role in a successful performance. He suggests practicing blind-folded is a painful but effective process of assimilation.

[Al Schmied was for many years the Head of the Music Department of the University of Tennessee, Knoxville.] 
15. Tallarico, P. Thomas. "A Study of the Three Phase Concept of Memory: Its Musical Implications.” Journal of Research in Music Education no. 39 (Fall 1974): 1-15.

An examination of the literature relating to the three-phase concept of memory: shortterm memory (STM), intermediate-term memory (ITM), and long-term memory (ITM). The discussion is followed by speculation as to the musical implications of this concept utilizing Grace Rubin-Rabson's experiment in $1940 .{ }^{18}$ The speculation has led to the assumption that it may be possible to increase teaching efficiency in certain areas of music instruction which depend on memorization of musical material. University.]

[P. Thomas Tallarico was Professor and Chair Emeritus at Bowling Green State

16. Guerrant, Mary T. "How Secure is Your Memory?" The Piano Quarterly 27, no. 106 (1979): 51.

A brief article on how to prevent memory "blackouts" and ways to memorize piano music. The author believes that purposeful playing of everyone note in the score is one of the most effective safeguards against memory lapses. The music must have a sense of direction, purpose, proportion, climaxes. Consistency of concentration is another important requirement for a fine performance. The author formulates some memorization techniques that will help performers to achieve this goal: study the score visually, play the left hand forte and the other hand as softly as possible and vice versa, play the piece with eyes closed, play silently, play the piece very slowly at pianissimo from memory, "hear" the music mentally and visualize how your hands look on the keyboard.

[No biography was found.]

17. Keeney, Wendell. "Memorizing and Memory Security." American Music Teacher 28, no. 3 (1979): 40-41.

An article on various ways of memorizing music and suggested memory tests to make certain that a piece is known on the level of every single note. The author suggests the actual process of memorizing does not require endless repetition if it incorporates a thorough knowledge of scales, chords and arpeggios with their fingerings, and musical analysis. J. S. Bach's Two-Part Invention in C major is used as a musical example.

[Wendell Keeney (1903-1989) was an American pianist and composer who studied composition with Rubin Goldmark and Nadia Boulanger and produced a number of beautifully crafted works. He was for many years chair of the music department at Furman University in Greenville, South Carolina. Later he moved to Washington, D.C., where he continued to teach privately. $\left.{ }^{19}\right]$

\footnotetext{
${ }^{18}$ Grace Rubin-Rabson, "Studies in the Psychology of Memorizing Piano Music: II. A Comparision of Massed and Distributed Practice." Journal of Educational Psychology XXXI (1940): 272-279.

${ }^{19} \mathrm{http} / / / \mathrm{www} . d r a m o n l i n e . o r g /$ content/notes/nwr/80304.pdf [Accessed 1 November 2011].
} 
18. Magrath, Jane. "Nerves, Memory, and Piano." American Music Teacher 32, no. 6 (1983): $17-18$.

A practical recommendation on how to overcome nervousness. This is crucial because nervousness may lead to memory lapses during a performance. The author suggests the quality of the preparation and practice are the critical elements for a successful performance. Before an actual recital, the pianist may practice performing by mentally imagining the performance situation or tape recording his program at home or in the studio. Playing through the recital program for people will also help the pianist to cope with the anxiety of performance. Lastly, one must discipline his mind not to wander from the music during the performance.

[Jane Magrath is well-known as an author, clinician, and pianist. Her book The Pianist's Guide to Standard Teaching and Performance Literature has become a classic reference work for pianists throughout the country. She currently has more than thirty-five volumes published with Alfred Publishing, and her music editions are used widely throughout the U. S. and abroad. She is Regents' Professor and holds the Grant Endowed Chair in Piano Pedagogy the University of Oklahoma. ${ }^{20}$ ]

19. Nuki, Michiko. “Memorization of Piano Music.” Psychologia 27 (1984): 157-163.

A case study designed to identify the abilities necessary in music memorization, superior methods for music memorization, and the structure of music which presents difficulties for memorization. A piano piece was specially commissioned for this study. Subjects consisted of seventeen piano students from Tokyo National University of Music and the Fine Arts, five compositions students from the same university, and eight piano students from two private music universities. Three important factors were made clear from the results of the experiment and survey: 1) Basic to memorization of the piano piece was solfège ablities, 2) The ability to thoroughly grasp musical structure through extensive training in harmony and compositional elements are factors in memorization, and 3) A high correlation between sight-reading abilities and memorization abilities was proved within the extent of the piece (which was based on functional harmony) used for this experiment.

[No biography was found.]

20. Sloboda, John A., B. Hermelin, and N. O'Connor. "An Exceptional Musical Memory." Music Perception 3 (1985): 155-170.

A study on the learning behavior of a musical idiot savant (NP) who is capable of memorizing large-scale pieces of piano music in three or four hearings. Attempts to memorize two contrasting pieces are documented. The first was op. 47 no. 3 ("Melodie") from Grieg's Lyric Pieces and the second was "Whole Tone Scale" from book 5 of Bartok's Mikrokosmos. The results are compared with those provided by a professional pianist. Transcription of the reproductions shows that NP's ability is constrained to tonal music and is structurally based. In this respect, it corresponds to the performance of high IQ memorizers and supports the view that

\footnotetext{
${ }^{20} \mathrm{http} / / /$ faculty-staff.ou.edu/M/Jane.J.Magrath-1/ [Accessed 13 February 2011].
} 
general intelligence is not necessary for the development of high levels of musical memorization skill.

[John A. Sloboda is Emeritus Professor at Keele, honorary Professor of Music at Royal Holloway University, London, and Visiting Research Fellow at the Guildhall School of Music \& Drama, London. He has been a member of the School of Psychology at Keele since 1974 and was Director of its Unit for the Study of Musical Skill and Development founded in 1991. John Sloboda is internationally known for his work on the psychology of music. $\left.{ }^{21}\right]$

21. Bliss, Russell A. "Developing a Better Memory by Making the Right Connections." The Piano Quarterly 37, no. 146 (1989): 48-49.

An analogy made between driving to a new destination and playing a piece of music from memory. The author suggests when the piece is new, the pianist is aware of every element that helps one memorize. As the music settles into the subconscious, these musical landmarks become less obvious. An awareness of how the two hands interact is one of the subtle devices to memorize piano music. Musical examples are taken from Brahms's Variations and Fugue on a Theme by Handel (mm. 8-9) and the first movement of Beethoven's Sonata in D major, Op. 10 No. 3 (mm. 74-78).

[Russell A. Bliss is a pianist living on Long Island. He received his doctorate from Columbia University where his project included an analysis and performance of Beethoven's last three sonatas. He is professor of music at Nassau Community College in Garden City and has taught a large class of private students for many years.]

22. Brodsky, Ellen A. "Memory Games for Young Students.” Clavier 29, no. 3 (1990): 18-19.

A presentation of three memory games utilized by author in her piano studio. "The Box" is used to isolate a particularly difficult section in a child's piece. The teacher may ask the student to memorize each hand of the boxed passage and then have her play the whole box by memory several times in the lesson. "Super-Quick Study" requires students to memorize on the spot a relatively easy piece based on a pattern or easy progression within five minutes, without ever playing through the music first. "Words of the Week" call for several terms relating to students' current repertoire. During the next few lessons, the teacher quizzes them at random.

[Ellen A. Brodsky received her D. M. A. from Stanford Unversity. An independent piano teacher in California, she also teaches at the Community School of Music and Art in Mountain View and performs as orchestral pianist with the Redwood Symphony.]

23. Jordan-Anders, Lee. “Stamp Out Memory-by-Default.” Clavier 29, no. 5 (1990): 32-35.

An article on teaching memory as an active skill by utilizing the senses of seeing, hearing, and feeling. The author suggests the sooner the students understand the importance of using not only their fingers, but also their brains, the sooner one can wipe out memory-by-default. The

${ }^{21} \mathrm{http}: / /$ www.iplevents.org/mms/sloboda [Accessed 25 July 2011]. 
author uses the composition Serge the Russian Bear by John Robert Poe as an example for teaching active memorization at the early levels.

[Lee Jordan-Anders is Batten Professor of Music and Artist-in-Residence at Virginia Wesleyan College in Norfolk, Virginia where she teaches courses in aesthetics, listening, music theory, chamber music, and applied piano. Her articles on various aspects of piano teaching have appeared in Clavier Magazine, and she is a frequent guest speaker and adjudicator for piano teachers' organizations. She continues to be an active performer and scholar, giving concerts and lectures throughout the United States. $\left.{ }^{22}\right]$

24. Lim, Serene and Louis G. Lippman. "Mental Practice and Memorization of Piano Music." The Journal of General Psychology 118 (January 1991): 21-30.

A study that examined the effect of mental practice on memorization of piano music. College piano performance majors attempted to play short, unfamiliar selections from memory after practicing for 10 minutes by playing the score, visually inspecting it, or listening to a recorded rendition while examining the score. When practicing mentally, subjects were encouraged to make use of visual, acoustic, and kinesthetic imagery. Results showed that physical practice led to the best performance. Listening to a model of ideal performance provided some benefit over visual inspection alone.

[Louis G. Lippman is Professor Emeritus at Western Washington University.]

[No biography was found for Serene Lim.]

25. Jacobson, Jeanine M. "Memorize and Remember." American Music Teacher 41, no. 4 (1992): 16-19.

A presentation of memory and learning principles, initial memory procedure, and memory games for continuity and security. The author believes that playing music at the piano from memory requires two types of learning. First, tactile and aural memory are combined with visual and intellectual memory to generate a complete and reliable memorization of the information. Teacher may help the student find the structural plan of the piece and divide the piece into short, logical learning units. Second, memory must be tested and drilled. This can be done through the use of various games. Allegro in $C$ by Alexander Reinagle is used as a musical example.

[Jeanine Jacobson gained much of her expertise in the field of piano pedagogy during her 25 years as an independent piano teacher. She pursued graduate work at the University of Minnesota and completed her doctorate at the University of Oklahoma. She subsequently served twenty-year tenure as Professor of Piano and Piano Pedagogy at California State University Northridge, where she currently holds the position of professor emeritus. $\left.{ }^{23}\right]$

\footnotetext{
${ }^{22}$ http://facultystaff.vwc.edu/ ljordananders/ [Accessed 8 June 2011].

${ }^{23} \mathrm{http}: / /$ www.alfred.com/img/authors/jacobson.html [Accessed 16 February 2011].
} 
26. Ford, John. “Many Ways to Memorize.” Clavier 35, no. 3 (1996): 24-26.

A discussion on various approaches to memorizing music by strengthening types of memory; visual or photographic memory, tactile memory, and auditory memory. The author suggests that a visual or photographic memory involves seeing complete pages of music in one's head and/or visually looking at the hands while playing. Tactile memory is an essential part of playing but also the least reliable. To develop strong visual and tactile memories a pianist should play a piece at slow as well as at fast tempos. According to the author, playing the music on a table top with and without the score will enhance one's auditory memory.

[John Ford has taught piano in schools and private studios. He is a member and former president of the North Shore Music Teachers Association in Illinois.]

27. Mastroianni, Thomas. "Memory and Anxiety." Piano \& Keyboard 181 (July/August 1996): 37-39.

A discussion on the relationship between anxiety and music memorization. Anxiety can alter the focus of attention. Often what the performer calls a memory slip is not at all the result of faulty memory storage, but simply a misdirection of attention or poor focus. The author explains briefly how human nervous systems handle the two body states (the anxious state and the calm state). He, therefore, suggests that performers need to learn how to retain the calm state in order to maximize memory performance on stage and trust that the work they have done will bring positive results.

[Thomas Mastroianni is President of the American Liszt Society, Director of Piano of the Amalfi Coast Music and Arts Festival, and Professor Emeritus at The Catholic University of America. He is a 1992 recipient of the Medal of the Hungarian Liszt Society. His piano performances, lectures, and master classes have been presented in 20 countries on four continents. $^{24}$ ]

28. Chaffin, Roger and Gabriela Imreh. "Understanding and Developing Musical Memory: The Views of a Concert Pianist and a Cognitive Psychologist." American Music Teacher 46, no. 3 (December 1996/January 1997): 20-25.

A presentation of a case study on how the general memory principles developed by psychologists apply to expert piano performance. The pianist (Imreh) recorded and evaluated her practice sessions when she was preparing for a public performance of the third movement of Italian Concerto by J. S. Bach. She identifies three distinctive stages involved in the process. The first stage contains the forming and remembrance of an enormous number of cues that include all aspects of musical memory. In the second stage, these cues become more automatic. In the last stage of the work, the attention should be directed toward the interpretative and expressive cues.

[Roger Chaffin is a teacher and researcher with the Department of Psychology at the University of Connecticut. His research interests have included the differences between linguistic and factual knowledge the involvement of semantic processes in word learning and definition

\footnotetext{
${ }^{24}$ http://thomasmastroianni.com/index.htm [Accessed 15 February 2011].
} 
and eye movements during the learning of a new word. Chaffin's largest and most recent body of research has concentrated on music performance.]

[Gabriela Imreh is a classically trained professional pianist. In addition to her performing and recording activities Imreh has served on the faculty at several universities, including a 2003 appointment as Guest Professor at the University of Connecticut.]

29. Hallam, S. "The Development of Memorisation Strategies in Musicians: Implications for Education.” British Journal of Music Education 14 (1997): 87-97.

An observation of strategies for memorizing music as expertise develops. Twenty-two professional freelance musicians, representatives of most instruments of the modern symphony orchestra including an organist and a conductor, and fifty-five string players, aged 6-18, were interviewed regarding their approaches to memorization. Automated repetitions were evident across the range of expertise. Aural and kinesthetic strategies were almost universally reported, visual and cognitive approaches less so, the latter only in the professionals.

[S. Hallam is Dean of Faculty and Professor of Education at Institute of Education, London. Her research interests comprise of disaffection from school (behaviour, attendance, exclusion), learning and understanding (studying, homework, practising, the role of feedback), ability grouping, music psychology and music education. ${ }^{25}$ ]

30. Mastroianni, Thomas. "Mind and Body: Can Musical Memory Be Manipulated?” Piano \& Keyboard 186 (May/June 1997): 20-21.

A suggestion that memory and learning can be manipulated. The author suggests that people remember what they pay attention to, thus manipulation refers to direction of attention. Musical analysis adds meaning to the notes on the page and "whatever is meaningful is easy to remember." Creativity also plays an important role to memory enhancement. Performers are encouraged to recreate the musical ideas rather than simply memorizing the notes.

[Thomas Mastroianni is President of the American Liszt Society, Director of Piano of the Amalfi Coast Music and Arts Festival, and Professor Emeritus at The Catholic University of America. He is a 1992 recipient of the Medal of the Hungarian Liszt Society. His piano performances, lectures, and master classes have been presented in 20 countries on four continents. $^{26}$ ]

31. Chaffin, Roger and Gabriela Imreh. "Pulling Teeth and Torture: Musical Memory and Problem Solving.” Thinking \& Reasoning 3, no. 4 (November 1997): 315-336.

A report on a concert pianist (Imreh) learning J. S. Bach's Italian Concerto (Presto). She videotaped herself throughout the process and commented on the problems she came across as she practiced. Some two years later, Imreh wrote out the first page of the score from memory. Her verbal reports were mostly related to recognizing familiar patterns and identifying the formal

\footnotetext{
${ }^{25} \mathrm{http}: / /$ www.ioe.ac.uk/staff/FFPS/FFPS_17.html [Accessed 22 March 2011].

${ }^{26} \mathrm{http}: / /$ thomasmastroianni.com/index.htm [Accessed 15 February 2011].
} 
structure in the early stage of learning, and using the structure as a retrieval scheme in the later stage of learning. Practice segments were more likely to start and stop at boundaries of the formal structure than at other locations, and recall was higher for the beginnings of sections than for later portions.

[Chaffin is a teacher and researcher with the Department of Psychology at the University of Connecticut. His research interests have included the differences between linguistic and factual knowledge the involvement of semantic processes in word learning and definition and eye movements during the learning of a new word. Chaffin's largest and most recent body of research has concentrated on music performance.]

[Gabriela Imreh is a classically trained professional pianist. In addition to her performing and recording activities Imreh has served on the faculty at several universities, including a 2003 appointment as Guest Professor at the University of Connecticut.]

32. Williamon, Aaron. "The Value of Performing from Memory." Psychology of Music 27 (1999): 84-95.

A case study on performances of the Preludes from Cello Suites I, II, and III by J. S. Bach across five separate circumstances, differing with respect to memorization and the presence of music stand. Fifty "musicians" and thirty-six "non-musicians" were asked to watch and rate one video-taped performance of each prelude on four performance aspects: overall quality, musical understanding, technical proficiency, and communicative ability. Ratings implied that performing from memory surpassed playing from the score, visibility of the performer influenced audiences' ratings of performances in a favorable direction, the extra time spent preparing for the memorized performances was worthwhile, and musicians seemed biased in favor of performances without a music stand. Similar research needs to be done on the value of performing from memory for pianists.

[Aaron Williamon is Professor of Performance Science at the Royal College of Music (RCM). His research focuses on skilled performance and applied scientific and health-related initiatives that inform music learning and teaching. In addition, he has performed as a trumpeter in chamber and symphony orchestras, brass bands, and brass quintets in both Europe and North America. ${ }^{27}$ ]

33. Sterba, Lydia S. "Shortcuts for Good Memorizing.” Piano Guild Notes 49 (6/2000): 4-5.

An article that offers various methods for accurate memorization. The author suggests that good memorization has the pre-requisite of a smooth and careful reading of notes, rhythm, and fingering. The author then explains the four categories of music memorization - analytical memorization, eye memorization, hand memorization, and ear memorization - and provides practice approaches on each category. Students should be encouraged to memorize as early as possible. As soon as the student understand how to shape his hands properly and can read both clefs, he is assigned a small section of one or two solos for his lesson each week.

[Lydia Sterba has recently retired from her teaching position at Morton College's piano department. She has been a soloist with several regional symphonies and orchestras in the

\footnotetext{
${ }^{27} \mathrm{http} / / / \mathrm{rcm}$.academia.edu/AaronWilliamon [Accessed 20 February 2011].
} 
Chicago area including the Chicago Symphony and Chicago Civic Orchestra. She has appeared in concert at Carnegie Hall in New York, receiving excellent critical reviews. She has given numerous lectures and served as an adjudicator in various piano contests at schools and colleges in the Chicago area, as well as serving as Guild adjudicator for annual auditions. She has a large class of talented students who have participated in Guild auditions and who have won various trophies, scholarships and grants throughout her years of teaching.]

34. Carni, Ellen I. "Eye Movements and Memory." Piano \& Keyboard 208 (January/February 2001): 19-20.

An introduction to EMDR (Eye Movement Desensitization and Reprocessing) method. Developed by psychologist Dr. Francine Shapiro in 1987 for the treatment of trauma survivors, it is now being used for more common conditions such as anxiety, depression, as well as for enhancing creativity and performance. Carni explained that EMDR sessions first evoke strong memories and emotions. By relieving past events with brain stimulation, you rid them of their disturbing power and allow in a flow of increasingly positive and hopeful thoughts, feelings, images, and anticipated events that your practitioner "installs" with more sets of brain stimulation.

[Ellen I. Carni is a clinical psychologist living in New York City.]

35. Chaffin, Roger and Gabriela Imreh. "Practicing Perfection: Piano Performance as Expert Memory." Psychological Science 13, no. 4 (July 2002): 342-349.

A study extending the principles of expert memory from domains that depend almost entirely on conceptual memory, like memory for chess and digit strings. A concert pianist (Imreh) recorded her practice as she learned the third movement, Presto, of J. S. Bach's Italian Concerto. She also described the formal structure of the piece and reported her decisions about fingerings, phrasings, and performance cues. Like expert memorists in other fields, the pianist in this study engaged in extensive practice in the use of a retrieval scheme to ensure that recall occurred rapidly and automatically.

[Chaffin is a teacher and researcher with the Department of Psychology at the University of Connecticut. His research interests have included the differences between linguistic and factual knowledge the involvement of semantic processes in word learning and definition and eye movements during the learning of a new word. Chaffin's largest and most recent body of research has concentrated on music performance.]

[Gabriela Imreh is a classically trained professional pianist. In addition to her performing and recording activities Imreh has served on the faculty at several universities, including a 2003 appointment as Guest Professor at the University of Connecticut.] 
36. Hughes, Walden. “The Benefits of Silent Practice.” Clavier 41, no. 8 (October 2002): 26-27.

A proposition on the main advantages of silent practice: improved concentration and increased confidence. The author suggests this practice can be done on any type of instrument, from a high-quality grand to a synthesizer with the sounds turned off. Student should also practice slowly at a $p p$ dynamic to evaluate his memory of a composition and identify problem spots in playing.

[Walden Hughes has published 75 articles and reviews (book and CD reviews) in national and international music journals. He holds five degrees in music, including two in piano performance and one each in piano pedagogy, music history and literature, and music theory. Hughes teaches piano, music history, composition and counterpoint at Northwest Nazarene University, where he has served for the past 33 years. $\left.{ }^{28}\right]$

37. Williamon, Aaron and Elizabeth Valentine. "The Role of Retrieval Structures in Memorizing Music.” Cognitive Psychology 44 (2002): 1-32.

A study that explores the use of structure in the encoding and retrieval of music and its relation to level of skill. Twenty-two pianists, categorized into four levels of skill, were asked to learn and memorize an assigned composition of J. S. Bach (different for each level). The data showed that the overall use of structural bars in starting and stopping practice segments increased with ability level, the use of structural bars developed with stage of practice, and the early use of structural bars to guide practice corresponded with quality of performance. These findings suggest that the identification and use of musical structure in guiding practice is a prominent characteristic of skill and becomes increasingly so as a function of expertise.

[Aaron Williamon is Professor of Performance Science at the Royal College of Music (RCM). His research focuses on skilled performance and applied scientific and health-related initiatives that inform music learning and teaching. In addition, he has performed as a trumpeter in chamber and symphony orchestras, brass bands, and brass quintets in both Europe and North America. $\left.{ }^{29}\right]$

[Elizabeth Valentine is Emeritus Professor of Psychology at Royal Holloway, University of London, United Kingdom. Her main research interest is in the development of scientific psychology in Britain, particularly London, during the first third of the twentieth century, with a particular focus on personal relationships. She is also interested in the psychology of music performance and have carried out a series of investigations on memory expertise. $\left.{ }^{30}\right]$

38. Highben, Zebulon and Caroline Palmer. "Effects of Auditory and Motor Mental Practice in Memorized Piano Performance." Bulletin of the Council for Research in Music Education 159 (Winter 2004): 58-65.

A study examining the effects of two types of mental practice in learning to perform an unfamiliar piece from memory: auditory and motor practice. Sixteen pianists performed

\footnotetext{
${ }^{28} \mathrm{http}: / /$ people.nnu.edu/wdhughes/ [Accessed 6 February 2011].

${ }^{29} \mathrm{http}: / / \mathrm{rcm}$.academia.edu/AaronWilliamon [Accessed 20 February 2011].

${ }^{30} \mathrm{http}: / / \mathrm{www}$. .rhul.ac.uk/psychology/staffdirectory/professorelizabethvalentine.aspx [Accessed 1 August 2011].
} 
unfamiliar music from notation during ten practice trials, with the presence or absence of auditory feedback and motor feedback (finger movements). Pianists were instructed to mentally practice the missing feedback. After the practice trials the pianists performed the pieces from memory under normal performance conditions. Four musical pieces were composed for the experiment, based on the compositional style of early Baroque organ works.

Data analysis showed that physical practice conditions (in which auditory and/or motor feedback were present) led to better performance recall than conditions with mental practice. Furthermore, pianists with strong aural skills were least affected in memory tests by removal of auditory feedback during practice. These findings suggest that an accurate auditory image is important for successful performance from memory.

[Zebulon Highben is a choral conductor, composer, and church musician. He is currently a D.M.A. student in choral conducting at Michigan State University, and also serves as Director of Music at First Presbyterian Church of Lansing and conductor of the Ingham Festival Chorale. Highben has taught at the University of Wisconsin River Falls, Luther Seminary, and the annual Lutheran Summer Music Academy and Festival, where he has been The Paul Bouman Chapel Choir Director since 2005. ${ }^{31}$ ]

[Caroline Palmer has served as Professor of Psychology and Canada Research Chair at McGill University in Montreal, Canada since 2003. Her research program combines two related issues in cognitive psychology: how people remember long sequences typical of speech and music, and how they produce those sequences. ${ }^{32}$ ]

39. Oura, Yoko and Giyoo Hatano. "Parsing and Memorizing Tonal and Modal Melodies." Japanese Psychological Research 46, no. 4 (November 2004): 308-321.

An investigation on how style-specific knowledge contributes to melodic memory. The main focus of the study was the contribution of parsing skills for transforming an authentic, novel melody into series of short, conventional tonal sequences for memorization. Two melodies of different styles, a tonal melody in the style of Western tonal music and a modal (Japanese traditional) melody, were used as materials. Participants consisted of nine undergraduate music majors who had more than 15 years of piano training and ten inexperienced students who had no or a much shorter experience in playing tonal music. Results indicate that stable parsing is a necessary, but not sufficient, condition for efficient melodic memory.

[Yoko Oura serves as Faculty of Education and Human Sciences at Niigata University, Japan. Her research interests include expertise in creative domains and the acquisition of music skills.]

[Giyoo Hatano is Professor at the University of the Air, Chiba City, Japan. His research interests include conceptual development, expertise, and literacy/numeracy acquisition. ${ }^{33}$ ]

\footnotetext{
${ }^{31} \mathrm{http}: / /$ www.lutheransummermusic.org/index.php?option=com_content\&task=view\&id=112\&Itemid=154 [Accessed 9 November 2011].

$32 \mathrm{http}: / /$ www.mcgill.ca/spl/palmer/ [Accessed 9 November 2011].

${ }^{33} \mathrm{http}: / /$ edr.sagepub.com/content/32/8/26.abstract [Accessed 6 June 2011].
} 
40. Duke, Robert A. and Carla M. Davis. "Procedural Memory Consolidation in the Performance of Brief Keyboard Sequences." Journal of Research in Music Education 54, no. 2 (Summer 2006): 111-124.

The first in a series of experiments that observes consolidation effects in simple and complex motor skills, including skills involved in music performance. Subjects were 49 righthanded non-music majors enrolled in music class at the University of Texas at Austin. Using two sequential key press sequences, the authors tested the extent to which subjects' performance on a digital piano keyboard changed between the end of training and retest on subsequent days. This study showed consistent, significant improvements referable to sleep-based consolidation effects, indicating that learning continued after the termination of practice during both the first and second nights of sleep following training.

[Robert A. Duke is Professor of Music and Human Learning at the University of Texas at Austin. He is the founder of the National Forum on Research in Motor Learning and Music, a research collaborative devoted to the study of motor skill development and procedural memory consolidation. He lectures frequently on the topics of human learning, systematic observation and evaluation, and behavior management, presenting workshops and teaching demonstrations throughout North America. ${ }^{34}$ ]

[Carla Davis Cash is Assistant Professor of Piano and Piano Pedagogy at Texas Tech University where she serves as chair of the keyboard division, coordinates the group piano program, and teaches undergraduate and graduate courses in pedagogy and applied music. ${ }^{35}$ ]

41. McLachlan, Murray. "Advanced Memory Techniques." International Piano 46 (July/August 2006): 40-41.

A description of a master class presenting fourteen steps or tips to memorizing music for pianists who have sufficient patience and determination. Some of the unusual suggestions are relax and take deep breaths while sitting at the piano (do this regularly throughout a practice session to improve memory), away from the piano, write out the fingering of each note then play (using the music) the passage on a table following the exact fingering, and lie down and "sing" the passage in one's head and aloud from memory. Four musical excerpts from different periods were chosen to illustrate the approach: the first movement of J. S. Bach's English Suite in A minor, the central section of Chopin's E-flat minor Etude op. 10 no. 6, the transition from chorale to fugue in Cesar Frank's Prelude, Chorale, and Fugue, and Shostakovich's Sonata no. 1.

[Murray McLachlan is a concert pianist who has received outstanding critical acclaim for intelligent and sensitive interpretations and superb technical ability. His prolific discography has received long-standing international recognition and includes over thirty commercial recordings, including the complete sonatas of Beethoven and Prokofiev and many rarities. ${ }^{36}$ ]

\footnotetext{
${ }^{34} \mathrm{http}: / /$ www.music.utexas.edu/directory/details.aspx?id=36 [Accessed 7 March 2011].

$35 \mathrm{http}: / / w w w . d e p t s . t t u . e d u / m u s i c / F a c u l t y / C a r l a C a s h . a s p$ [Accessed 10 March 2011].

${ }^{36}$ http://www.murraymclachlan.com/biography.htm [Accessed 15 July 2011].
} 
42. Duke, Robert A. and Amy L. Simmons. "Effects of Sleep on Performance of a Keyboard Melody." Journal of Research in Music Education 54, no. 3 (Fall 2006): 257-269.

The first demonstration of consolidation-based enhancement of motor skills in the context of music. 75 music majors at the University of Texas at Austin learned a twelve-note melody on the piano and recalled the melody following 12- or 24-hour intervals that either did or did not include sleep. All were non-pianists with no training on the piano beyond four semesters of group piano instruction. This study has led to a speculation that perhaps new, intricate motor tasks are best learned with intervening intervals of sleep between their introduction and recall in later practice.

[Robert A. Duke is Professor of Music and Human Learning at the University of Texas at Austin. He is the founder of the National Forum on Research in Motor Learning and Music, a research collaborative devoted to the study of motor skill development and procedural memory consolidation. He lectures frequently on the topics of human learning, systematic observation and evaluation, and behavior management, presenting workshops and teaching demonstrations throughout North America. ${ }^{37}$ ]

[Amy L. Simmons serves as Assistant Professor of Instrumental Music Education at Texas State University. She is currently the Chair for the Instructional Strategies Research Interest Group for the MENC: National Association for Music Education, and has been a longtime member of the State Research Committee for the Texas Music Educators Association. ${ }^{38}$ ]

43. Chaffin, Roger and Gabriela Imreh. "Learning Clair de Lune: Retrieval Practice and Expert Memorization." Music Perception: An Interdisciplinary Journal 24, no. 1 (April 2007): 377-393.

A case study examining the relationship between three principles of expert memory (use of familiar patterns to encode new information, use of retrieval scheme, and extended retrieval practice) and memorization of piano music. A concert pianist (Imreh) recorded her practice as she learned Clair de Lune by Claude Debussy. She also provided detailed reports on the formal structure of the piece, the performance cues, and other decisions about technique and interpretation. The study has shown that musicians' use of musical structure and performance is coherent with principles of expert memory developed from the study of experts in other fields and with principles of memory derived from the study of general population.

[Chaffin is a teacher and researcher with the Department of Psychology at the University of Connecticut. His research interests have included the differences between linguistic and factual knowledge the involvement of semantic processes in word learning and definition and eye movements during the learning of a new word. Chaffin's largest and most recent body of research has concentrated on music performance.]

[Gabriela Imreh is a classically trained professional pianist. In addition to her performing and recording activities Imreh has served on the faculty at several universities, including a 2003 appointment as Guest Professor at the University of Connecticut.]

\footnotetext{
${ }^{37} \mathrm{http}: / /$ www.music.utexas.edu/directory/details.aspx?id=36 [Accessed 7 March 2011].

${ }^{38} \mathrm{http} / / / \mathrm{www} . \mathrm{music}$. txstate.edu/facultystaff/bios/simmons.html [Accessed 7 March 2011].
} 
44. Mishra, Jennifer and William W. Backlin. "The Effects of Altering Environmental and Instrumental Context on the Performance of Memorized Music." Psychology of Music 35, no. 3 (July 2007): 453-472.

A study involving three experiments to determine whether musical memory was context dependent. Musicians were asked to learn short and relatively simple exercises. Audience was omitted from this study to avoid confounding variables. Contexts comprised the following performing environments: lobby/conference room for experiment 1 and practice room, professor's studio, stage for experiment 2. Experiment 3 extended the definition of 'context' to include instrument. Participants learned a 16-bar piano composition on either a grand piano (context A) or an upright studio piano (context B) and then were asked to recall on either the same piano (conditions $\mathrm{AA}$ and $\mathrm{BB}$ ) or the different piano (conditions $\mathrm{AB}$ and $\mathrm{BA}$ ). Results showed that pianists who learned and performed on the same piano performed more accurately than pianists who changed to a different piano.

[Jennifer Mishra is Associate Professor and Coordinator of Music Education at the University of Houston. Her research interests are in the area of music cognition, specifically focusing on performance memory. $\left.{ }^{39}\right]$

[William W. Backlin is Professor of Piano Studies, Music Theory and Music History at the North Iowa Area Community College. ${ }^{40}$ ]

45. Mishra, Jennifer. "A Century of Memorization Pedagogy." Journal of Historical Research in Music Education 32, no. 1 (October 2010): 3-18.

An observation of trends of pedagogical writing on musical memorization between 1872 and 2006. Articles written by musicians and music teachers and published in English language periodicals or as book chapters were subjected to a content analysis $(\mathrm{N}=185)$. The majority $(60$ percent) of the articles focused on memorizing for keyboard instruments (piano or organ). Many articles were instrument-nonspecific (16 percent), emphasizing memorization as a process rather than as a specific instrument technique. A handful of articles focused on memorizing for certain instruments (strings/guitar, woodwinds/recorder, brass/percussion), including conducting. Only a few articles were devoted to vocal memorization (3 percent).

[Jennifer Mishra is Associate Professor and Coordinator of Music Education at the University of Houston. Her research interests are in the area of music cognition, specifically focusing on performance memory. ${ }^{41}$ ]

\footnotetext{
${ }^{39} \mathrm{http} / / / \mathrm{www} . \mathrm{music}$. uh.edu/people/mishra.html [Accessed 20 April 2011].

${ }^{40} \mathrm{http}: / / \mathrm{www} \cdot$ niacc.edu/music/faculty.html [Accessed 20 April 2011].

${ }^{41} \mathrm{http} / / / \mathrm{www} . \mathrm{music} . u h . e d u /$ people/mishra.html [Accessed 20 April 2011].
} 


\section{Chapter IV}

\section{Annotated Bibliography - Theses/Dissertations}

1. Erskine, Martha. "Harmonic Analysis as an Aid to Memorizing Piano Repertoire." M.M. thesis, University of Arizona, 1942.

A case study of the relative effectiveness of harmonic analysis among several methods of music memorization. Data was collected from interviews with and observations of five piano teachers, eight concert artists, and a number of conservatory and college piano students over a period of ten years. Four methods of or devices for music memorizing were found from this data. Method I consisted of memorizing a piece of music as a whole by means of repetition. Method II involved conscious memorizing of openings of passages or sections. Method III was photographic memory, namely "seeing" or recalling a "mentally photographed" image of the score. Method IV was the committing of material to memory through interest in the subject derived from appreciation of the harmonic structure of the composition. The author concluded that the method of memorizing piano repertoire with the aid of harmonic analysis was the most secure.

[No biography was found.]

2. Von Grabow, Richard H. "A Brief Study of Mental Processes as Applied to the Memorization of Compositions for the Piano." M.A. thesis, Ball State University, 1958.

A study that compares terms and theories of educational psychologists with the practices of pianists on memorization and attempts to apply the psychologist's standardized terms and theories to memorization in musical endeavors such as the author's graduate piano recital. The psychologists accentuate the correlation, integration and associative transfer of material in learning situations and de-emphasize repetitive drill. On the other hand, piano teacherperformers stress mastery of detail and repetitive drill. The author believes that memorization by repetitive methods followed by recall of the mental images associated with the learning resulted in more accurate retention of the music.

[Richard von Grabow is Emeritus Carillonneur and Professor of Music History and Literature, Iowa State University. He joined the faculty of the Music Department in 1969, was appointed University Carillonneur in 1973, and retired in $1991 .{ }^{42}$ In addition to performing throughout the United States, Grabow published carillon music arrangements which added significantly to the published carillon music repertoire. He currently resides in Benicia, California. ${ }^{43}$ ]

\footnotetext{
${ }^{42} \mathrm{http} / / / \mathrm{www} . \mathrm{music}$.iastate.edu/carillon/festival/festival1995/festival.pdf [Accessed 19 November 2011].

${ }^{43} \mathrm{http} / / / \mathrm{www} . \mathrm{music}$.iastate.edu/carillon/carillonneurs.php [Accessed 19 November 2011].
} 
3. Nellons, Charles Edward. "An Experimental Investigation of the Effect of Blocking on the Memorization of Selected Piano Literature.” D.Mus.Ed. diss., University of Oklahoma, 1974.

A study that examined the effect of a blocking procedure on the number of repetitions and the amount of practice time required for the memorization of selected piano repertoire, as well as on retention accuracy. The term blocking refers to the practice of identifying note groups according to hand positions by means of recognizing scale patterns as clusters; recognizing intervals, arpeggios and chord fragments as solid chords; and identifying and classifying compositional devices by the composer.

Participants were twenty-two undergraduate music education majors enrolled at Texas Southern University, Houston, Texas. Three compositions were selected for the experiment: Diversions no. 2 by Richard Rodney Bennett, The Rain and the Rainbow op. 65 no. 8 by Sergei Prokofiev, and Prelude in E minor by Domenico Zipoli. Analysis of the data disclosed that blocking allowed for a requisite number of repetitions to be completed in less time. While no definite conclusion can be drawn, the obtained data appears to indicate that there is little difference between the groups in retention accuracy after seventy-two hours.

[No biography was found.]

4. Schlabach, Eugene L. "The Role of Auditory Memory in Memorization at the Piano." Ed.D. Thesis, University of Illinois at Urbana-Champaign, 1975.

A study that investigated the role of auditory memory and tested its effect on learning and relearning of four methods of instruction. The four methods included aural analysis, visual analysis, combined aural and visual analysis, and direct keyboard practice. A Graeco-Latin square was used so that twenty-four subjects learned four piano compositions on four different days, using a different method each time. Subjects were serious music students planning to become professional musicians and music teachers. The four compositions were Gavotte by Reinagle, Old Polish Dance and Rondo by Benjamin Carr, and Unexpected Visitor from Beethoven's Sketchbooks. They were sixteen measures in length. Each had a dominant melodic line and chordal or broken-chord accompaniment patterns.

The multiple correlation coefficients showed that tonal memory and rhythmic discrimination were benefits in learning by aural and visual methods while keyboard fluency and rhythmic sensitivity were important to learning by combined aural and visual and direct keyboard methods. Based on the results of the study, the experimenter author concluded that the effectiveness of the method is influenced by individual abilities, composition difficulty levels, and the specific content of compositions and analysis.

[Eugene Schlabach has held the position of Instructor in piano, theory, and music history at Triton College, River Grove, Illinois since 1966. He was choral director in Waverly public schools, Waverly, Illinois from 1958 to 1961. In 1961, he became instructor in piano and theory Central Florida Junior College, Ocala, Florida.] 
5. Lo, Lawrence Naai-Lei. "The Effect of Visual Memory Training on the Ability to Memorize Music within Class Piano Instruction.” D.Mus.Ed. diss., Indiana University, 1976.

An experiment designed to determine whether study of the score followed by attempts to visualize the score with eyes closed would aid college students studying secondary piano in the memorization of four-part hymns similar to the patriotic songs they were required to memorize. The area of investigation was limited to short-term recall or immediate memory. The study did not attempt to explore visual memory as an asset to the memorization of advanced piano literature.

Six second-semester piano classes at the Indiana University School of Music participated in the experiment. The number of students completing the experiment was 14 in the control group and 16 in the experimental group, each with an equal number of male and female students. The criteria used for judging the taped performances were total accuracy score or perfect score, rhythm score, melody score, and chord score. The experimental group, which received specific instruction to memorize musical examples visually, improved more than the control group, which did not receive this instruction, in every instance.

[No biography was found.]

6. Shockley, Rebecca P. "An Experimental Approach to the Memorization of Piano Music with Implications for Music Reading." D.M.A. diss., University of Colorado at Boulder, 1980.

A study that represents an attempt to examine common methods of memorizing music and to explore alternative procedures. Evidence was presented to support the hypothesis that many memory problems originate from the repetition methods for memorizing frequently applied after music has been learned. An alternative approach to learning music was constructed, involving improvisation and the preparation of a visual abstract of the score away from the keyboard, prior to playing, in order to stimulate pattern awareness.

The procedure was tested on twenty-eight students enrolled in piano classes at the University of Colorado using a pre-test post-test quasi-control group design. Participants were given a sight-reading task and a memorization task at the beginning and conclusion of the threeweek experiment. All tests were individually tape recorded and later scored for comparison purposes. Students in the experimental group received practice sessions using the experimental approach to music learning outlined above as a part of their piano class curriculum. Each participant also completed a set of questionnaires before and after the experiment as a subjective measurement of achievement. Although the results are somewhat inconclusive, they do suggest gains in memorization ability and improved reading habits resulting from use of this method.

[Rebecca Shockley is Professor of Piano Pedagogy and Coordinator of Class Piano at the University of Minnesota. She has given presentations on music learning for colleges, universities, and music teacher organizations across the U.S. and in England, Canada, Taiwan, China and Korea. An active member of Music Teachers National Association, Shockley chaired the Pedagogy Saturday Committee for two years and previously served on the National Convention Program Committee. For twelve years she also chaired the Committee on Learning Theory for the National Conference on Piano Pedagogy. She has given clinics for Frederick Harris and the Lorenz Corporation, and she served on the Advisory Board for Piano Discoveries, a recent piano 
method published by Lorenz. Shockley is the author of Mapping Music: For Faster Learning and Secure Memory - A Guide for Piano Teachers and Students, (A-R Editions, 1997, 2001). Her book was also published in a Korean translation by Hanyang University Press in $2002 .{ }^{44}$ ]

7. Wilson, John Paul. "The Effect of Sleep and Time on Music Memory." Ph.D. Thesis, University of Texas at Austin, 1980.

An experiment that was designed to examine the effect sleep and waking activity would have upon retention of memorized melodies learned to criterion at the piano. Ten subjects memorized five melodies each at the piano, and retention intervals of $8,24,48,72$, and 168 hours were utilized. Learning occurred under one of the two experimental conditions: learning prior to sleep or learning at the beginning of a period of waking activity. Data analysis indicated that there was no significant difference in the time or trials to attain criterion in the learning session. However, a considerable difference did exist for trials to recall criterion. The waking condition required greater number of trials. There was also a substantial variance in rhythmic accuracy, melodic accuracy, and combined accuracy, favoring the sleep condition. Sleep is superior to waking at the 8 -hour interval, reaches its maximum differential at 24 hours, and then declines through 48 and 72 hours. Data collected also provided a comparison with other studies of the "Kamin Effect," characterized by a U- or V-shaped retention curve.

[No biography was found.]

8. Jones, Alfred R., III. "The Role of Analytical Pre-Study in the Memorization and Retention of Piano Music with Subjects of Varied Aural/Kinesthetic Ability." Ph.D. diss., University of Illinois at Urbana-Champaign, 1990.

A study that investigated the relationship of four methods of analytical pre-study to the time and number of trials required for pianists with diverse aural/kinesthetic $(\mathrm{A} / \mathrm{K})$ ability, or the ability to play "by ear," to memorize four piano compositions and to relearn these same compositions after a period of three to four weeks. Data analysis revealed that (a) pre-study of compositions before memorization had no effect on either memorization or re-memorization, and (b) subjects with high $\mathrm{A} / \mathrm{K}$ ability required significantly fewer repetitions to re-learn the compositions. The procedure for the main study closely followed the procedures used in Rubin Rabson's 1937 investigation of pre-study in memorizing piano music.

[No biography was found.]

9. Rickey, Eunice L. "An Investigation to Observe the Effects of Learning Style on Memorization Approaches Used by University Group Piano Students When Memorizing Piano Literature.” D.A. diss., Ball State University, 2004.

A study that observed which approaches to memorization were being used by group piano students and which approaches were most effective in short memorization tasks. Seventeen group piano students enrolled at Indiana Wesleyan University were tested for their learning style

${ }^{44}$ https://music.umn.edu/people/faculty-staff/profile?UID=shock001 [5 April 2011]. 
preferences and then were given a sample of music to memorize. Each subject completed a brief experience and task ease pretest, an interview while observing the video of what took place during the memorization process, and a posttest questionnaire on learning approaches used.

Subjects who were observed for this research had a tendency to memorize more from the visual and tactile approaches. Findings in the posttest questionnaire indicated that the majority of subjects used aural and/or visual approaches as their preferred ways of memorizing. This research showed that there was more tendency for subjects using visual memory approach to receive the best memory scores (excellent, no errors). This study also indicated that students using the analytical approach to memory tended to have the highest percentage of best performance score (two of three received excellent or no errors scores).

[Eunice Rickey is Professor of Music at Indiana Wesleyan University where she teaches piano courses and Senior Seminar. She is director of the annual IWU Piano Pedagogy Conference and Coordinator of the IWU Music Academy. Rickey's scholarship endeavors lie in the field of pedagogy. She has served on Indiana Music Teachers Association committees and co-directed an annual conference also for the IMTA. $\left.{ }^{45}\right]$

10. Sharpe, David D. "Applications to the Pedagogy of Memory and Piano Playing: Building Solid Foundations.” D.M.A. diss., Arizona State University, 2004.

A document that explores the process of memorizing piano music and offers useful strategies for students and teachers achieving this goal. Three repertoire samples from different musical periods are used to illustrate various strategies for memorization. For each example, a discussion of possible approaches one could use to memorize the music is given with reference to building visual, aural, kinesthetic, and conceptual memory. The works involved are: 1) J. S. Bach's Minuet III in G major, from Suite in G minor, BWV 822, 2) Leonard Bernstein's Five Anniversaries no. 5: For Susanna Kyle, 3) Schumann's Fantasiestücke (Fantasy Pieces) op. 12 no. 2: Aufschwung (Soaring). Additional topics included are the workings of human memory and memory building principles and strategies as applied to piano music.

[David Sharpe was three-time state collegiate winner for Arizona in piano in the MTNA performance competitions, winner of the Atlantic Young Artists Competition, and has performed, taught, presented and judged throughout the US, Canada and in Europe. He is a senior examiner for RCM examinations, periodically examining candidates through the US and Canada. Sharpe is also an attorney at law in Tampa, Florida. ${ }^{46}$ ]

11. Davis, Carla M. "Effects of Early and Late Rest Intervals on Performance and Consolidation of a Keyboard Sequence." Ph.D. diss., University of Texas at Austin, 2007.

Two experiments that involved non-musicians practicing a 5-note sequence with their left (non-dominant) hand on a digital piano, designed to observe the extent to which 5-minute rest intervals placed early and late during practice influence motor sequence learning. The sound variable was eliminated in an attempt to focus specifically on the development of motor skills. The introduction of extended rest in the early and late stages of practice significantly affected the rates of learning within and between sessions, with large improvement favoring the early rest

\footnotetext{
${ }^{45} \mathrm{http} / / / \mathrm{www}$. indwes.edu/Academics/Faculty-Profiles/?facProfile=euni.rickey [Accessed 12 September 2011].

${ }^{46} \mathrm{http}: / /$ www.dariodiazlaw.com/english/our-staff/david-sharpe.php [Accessed 22 September 2011].
} 
group. These findings suggest that neurophysical processes that occur during 5-minute rest intervals enhance performance and that the temporal placement of rest in a training session affects subsequent motor sequence learning and the consolidation of procedural memories.

[Carla Davis Cash is Assistant Professor of Piano and Piano Pedagogy at Texas Tech University where she serves as chair of the keyboard division, coordinates the group piano program, and teaches undergraduate and graduate courses in pedagogy and applied music. $\left.{ }^{47}\right]$

12. Simmons, Amy L. "Effects of Practice Variability and Distribution of Practice on Musicians' Performance of a Procedural Skill." Ph.D. diss., University of Texas at Austin, 2007.

A study designed to examine how procedural memory consolidation in a music task is affected by practice under different conditions of speed regulation and different time intervals between practice sessions. Ninety-two non-pianist musicians practiced a 9-note sequence with their non-dominant hand on a digital piano in three sessions, each of which comprised 3 blocks of 15 performance trials. In Experiment $1(n=31)$, participants were instructed to perform as quickly and accurately as possible but determined their own tempos in each trial. In Experiment $2(\mathrm{n}=31)$, three defined practice tempos were externally regulated in a stable practice procedure in which tempo changed between, not within, blocks. In Experiment $3(n=30)$, the same three tempos were externally regulated in a variable practice procedure in which practice tempo changed from trial to trial within each block. In each experiment, three different groups' practice sessions were separated by either $5 \mathrm{~min}, 6 \mathrm{hr}$, or $24 \mathrm{hr}$.

The results demonstrate that motor skill learning in music is affected by the time interval between practice sessions, and that the effects of distributed practice are dependent upon practice conditions. Perhaps new music tasks are best learned with intervening intervals of sleep between their introduction and recall in later practice. Distributing practice across time that allows consolidation to stabilize and enhance procedural memories may even increase the efficiency of musicians' practice time.

[Amy Simmons is Assistant Professor of Instrumental Music Education at Texas State University. She also serves as the Chair for the Instructional Strategies Research Interest Group for the MENC: National Association for Music Education, and has been a long-time member of the State Research Committee for the Texas Music Educators Association. ${ }^{48}$ ]

13. Allen, Sarah E. "Procedural Memory Consolidation in Musicians." Ph.D. diss., University of Texas at Austin, 2008.

A study that tested the extent to which a music performance skill was enhanced from sleep-based consolidation overnight and whether this process may be interfered when musicians learn two melodies in juxtaposition. Sixty experienced musicians, all non-pianists, learned to perform either one or two 13-note piano melodies during evening training sessions. The musicians practiced each melody with their non-dominant hand by repeating it from beginning to end during twelve 30 -second practice blocks alternating with 30 -second rest intervals. All participants were retested on the target melody the following morning in three 30 -second retest blocks alternating with 30 -second rest intervals. The results suggest that experienced learners

\footnotetext{
${ }^{47} \mathrm{http}: / /$ www.depts.ttu.edu/music/Faculty/CarlaCash.asp [Accessed 10 March 2011].

${ }^{48} \mathrm{http}: / /$ www.music.txstate.edu/facultystaff/bios/simmons.html [Accessed 2 October 2011].
} 
performing a familiar type of task, and one that includes auditory processing demands, benefit from overnight consolidation of procedural memories. These benefits may be inhibited, however, when musicians learn similar, competing tasks in juxtaposition.

[Sarah Allen is Assistant Professor of Music Education at Southern Methodist University. $\left.{ }^{49}\right]$

\section{CHAPTER V}

\section{Summary and Conclusion}

${ }^{49} \mathrm{http} / / /$ www.smu.edu/Meadows/AreasOfStudy/Music/Faculty/AllenSarah.aspx [Accessed 2 October 2011]. 
Memory is something we were born with, but, to develop it, a technique of memorization must be acquired; like conscious practicing, it can be developed to a remarkable degree.

- György Sándor ${ }^{50}$

Music memorization, especially for pianists, has been a continuing research interest since the late 1890s. The numerous amounts of scholarly books, journal articles, and thesis/dissertations written on this intriguing topic show the broad interest by performers, teachers, students and scientists. This research project provides reviews of 76 resources that are directly related to memorization of piano music from both musical and psychological points of view.

\begin{tabular}{|l|c|c|c|c|}
\hline & Books & Articles & Theses/Dissertations & Total \\
\hline Before 1900 & 1 & -- & -- & 1 \\
\hline $1901-1910$ & 2 & -- & -- & 2 \\
\hline $1911-1920$ & -- & 1 & -- & 1 \\
\hline $1921-1930$ & 1 & -- & -- & 1 \\
\hline $1931-1940$ & 2 & 3 & -- & 5 \\
\hline $1941-1950$ & 2 & 5 & 1 & 8 \\
\hline $1951-1960$ & 1 & 1 & 1 & 3 \\
\hline $1961-1970$ & 1 & 2 & 5 & 5 \\
\hline $1971-1980$ & -- & 5 & -- & 9 \\
\hline $1981-1990$ & 2 & 6 & 1 & 11 \\
\hline $1991-2000$ & 1 & 10 & -- & 22 \\
\hline $2001-2010$ & 5 & 12 & 5 & 76 \\
\hline
\end{tabular}

Table 1. Breakdown by decade of the number of books, articles, and theses/dissertations written on memorization of piano music included in this research project

\section{Common Traits}

Four Elements of Memory

\footnotetext{
${ }^{50}$ György Sándor, On Piano Playing: Motion, Sound, and Expression (New York: Schirmer Books, 1981), 192.
} 
Scholars have agreed that there are four types of memory involved in the memorization of piano music: aural memory, visual memory, tactile or kinesthetic memory, and intellectual or analytical memory. Aural memory is the ability to recall the sound of music in detail and nuance (including what the pianist is listening to and listening for). It obviously plays an important role for musicians and can be enhanced by ear training. Visual or photographic memory involves seeing complete pages of music or sections of it in one's head while playing and/or visualization of hand placements on the keys. Tactile or kinesthetic memory is a significant part of playing but also the least reliable. Often referred to as "motor memory", it is generally agreed that it is the most basic and essential part of memorization but must be reinforced by the other three forms of memory. Analytical or intellectual memory requires understanding of harmonic, melodic, rhythmic, and formal musical structure. To achieve maximum memory consolidation, one needs to strengthen each of these four elements of memory with all the conscious attention they call for.

\section{The Sense of Hearing}

Musicians rely on their ears while playing their instruments. After all, music is enjoyed through listening. Zebulon and Palmer ${ }^{51}$ conducted a study where sixteen pianists performed unfamiliar music from notation, with the presence or absence of auditory feedback and motor feedback (finger movements). After the practice trials the pianists performed the pieces from memory under normal practice conditions. Their findings suggest that an accurate auditory image in the initial memorization process is important for successful performance from memory.

\footnotetext{
${ }^{51}$ Zebulon Highben and Caroline Palmer. "Effect of Auditory and Motor Mental Practice in Memorized Piano Performance," Bulletin of the Council for Research in Music Education 159 (Winter 2004): 58-65.
} 
Ford ${ }^{52}$ recommends playing the music on a table top and without the score to enhance one's auditory memory.

\section{The Sense of Visualization}

The ability to visualize complete pages of music or sections of it in one's head is rare. The more common use of visual memory is recognizing the hand placements on the keyboard which serves as a guide to other memory abilities.

\section{The Sense of Feeling}

Refined motor skills are required for playing any musical instrument. Countless hours of practicing are dedicated to achieve such perfection. Studies show that consistent fingerings will strengthen kinesthetic memory. Also, an experiment based on a simple 16-bar piano composition showed that pianists who learn and perform on the same type of piano will recall more accurately than pianists who change to a different type of piano (upright vs. grand piano) ${ }^{53}$.

The Role of Analytical Pre-Study in Memorizing Piano Music

Analytical pre-study is one element often neglected by pianists. Grace Rubin-Rabson, in The Influence of Analytical Pre-Study in Memorizing Piano Music in 1937, discovered that the method of memorization which included an analysis by the subject proved superior to the method without such analysis. Even inexpert and inexperienced analysis is much better than

\footnotetext{
${ }^{52}$ John Ford, "Many Ways to Memorize," Clavier 35 no. 3, 1996, 24-26.

${ }^{53}$ Jennifer Mishra and William Backlin. "The Effects of Altering Environmental and Instrumental Context on the Performance of Memorized Music," Psychology of Music 35 no. 3, July 2007, 453-472.
} 
none at all. Other scholars who support this proposition include Martha Erskine ${ }^{54}$, Charles Nellons ${ }^{55}$, and Eunice Rickey ${ }^{56}$. Further, Rebecca Shockley developed a tool to help pianists develop their own approach to mapping a piece of music ${ }^{57}$. It is a simple strategy for learning and memorizing music more efficiently by diagramming the main elements of a piece and using this diagram as a "map."

\section{A Rise of Interest and Recent Development in the Research for the Past Decade}

Table 1 shows that the number of studies on memorization of piano music doubled in the past decade with two areas dominating the literature: expert memory and piano performance, and the effect of sleep and time on musical memory.

\section{Expert Memory and Piano Performance}

General theories of expert memory involving the use of familiar patterns to encode new information, use of a retrieval scheme, and extended retrieval practice have proven to be compatible with musicians' use of musical structure and performance from memory. Aaron Williamon and Elizabeth Valentine explored the use of structure in the encoding and retrieval of music and its relation to the level of skill in $2002^{58}$. Their findings suggest that the identification and use of musical structure in guiding practice is a valuable skill and becomes increasingly so as a function of expertise. Roger Chaffin (a cognitive psychologist) and Gabriela Imreh (a concert

\footnotetext{
${ }^{54}$ Martha Erskine, "Harmonic Analysis as an Aid to Memorizing Piano Repertoire" (M.M. thesis, University of Arizona, 1942).

${ }^{55}$ Charles Nellons, "An Experimental Investigation of the Effect of Blocking on the Memorization of Selected Piano Literature" (D.Mus.Ed. diss., University of Oklahoma, 1974).

${ }^{56}$ Eunice Rickey, "An Investigation to Observe the Effects of Learning Style on Memorization Approaches Used by University Group Piano Students when Memorizing Piano Literature" (D.A. diss., Ball State University, 2004).

${ }^{57}$ Rebecca Shockley, Mapping Music for Faster Learning and Secure Memory: A Guide for Piano Teachers and Students (Madison: A-R Editions, Inc., 1997).

${ }^{58}$ Aaron Williamon and Elizabeth Valentine, "The Role of Retrieval Structures in Memorizing Music," Cognitive Psychology 44, 2002, 1-32.
} 
pianist) agree that pianistic memory appears to be based on the use of a highly practiced retrieval scheme which permits rapid retrieval of information from long-term memory, like other forms of expert memory ${ }^{59}$.

\section{The Effect of Time and Sleep on Musical Memory}

Memorization implies not only the ability to store music but also the ability to bring it back - to perform it ${ }^{60}$. In 1980, John Paul Wilson designed an experiment ${ }^{61}$ to examine the effect of sleep and waking activity would have upon retention of memorized melodies learned at the piano. Ten subjects memorized five melodies each at the piano, and retention intervals of 8,24 , 48,72 , and 168 hours were utilized. Learning took place under one of the two experimental conditions: learning prior to sleep or learning at the beginning of a period of waking activity. The waking condition required greater number of trials in the recall session. There was also a considerable variance in rhythmic accuracy, melodic accuracy, and combined accuracy, favoring the sleep condition. At the turn of the $21^{\text {st }}$ century, similar research interests continued to grow. Robert Duke, Amy Simmons, Carla Davis, and Sarah Allen conducted a series of experiments that tested the effects of rest intervals and sleep on musicians' performance of a procedural skill. These studies suggest that distributing practice across time allows consolidation to stabilize and enhances procedural memories.

\footnotetext{
${ }^{59}$ Roger Chaffin and Gabriela Imreh. "Pulling Teeth and Torture: Musical Memory and Problem Solving," Thinking and Reasoning 3 (4), 1997, 315-336.

${ }^{60}$ György Sándor, On Piano Playing: Motion, Sound, and Expression (New York: Schirmer Books, 1981$), 192$.

${ }^{61}$ John P. Wilson,. "The Effect of Sleep and Time on Music Memory" (Ph.D. Thesis, University of Texas at Austin, 1980).
} 


\section{Conclusion}

Resources annotated in this research project suggest that memorization is best approached in a meaningful and musical way. Memorization is part of the music-making process. It is an outcome of all skills and understanding which constitute total musicianship as applied to learning. Strengthening all areas of musical skills, including reading, improvising, playing by ear, and analysis, can lead to significant improvements in memorization. ${ }^{62}$

Many pianists struggle with memorizing their music because they rely solely on muscle memory. Piano performance, though seemingly kinesthetic, is based on a high degree of organizational skill in the learning. It is advisable for teachers to introduce the concept of music analysis as early as possible and to request students to memorize their music often. For young students, music analysis can be introduced through mapping music and/or varieties of memory games.

It is interesting to note areas that were not covered by resources discovered in this research project. First concerns the order of material for memorization, such as the effectiveness of memorizing from beginning to end or memorizing the end or the most challenging sections first. Second concerns the selection of repertoire for developing effective memorization skills. For example, the effectiveness of studying music that contains much repetitive material (such as an easier Chopin Waltz) first before learning and memorizing a more complex work (such as a Bach fugue). A third possible direction is memorization of non-tonal piano music. Do the techniques discussed in these resources apply to pieces with non-functional harmony?

Memorizing music requires patience and time. The pianist may try all memorization techniques offered out there. In the end, the brain and body need some time to process the new

\footnotetext{
${ }^{62}$ Rebecca Shockley, "An Experimental Approach to the Memorization of Piano Music with Implications for Music Reading” (D.M.A. diss., University of Colorado at Boulder, 1980), 28.
} 
information and automatically retrieve it when needed. Despite the disagreement whether or not pianists should memorize their music when they will be performing it, memorizing promotes mastery and understanding of the music and is therefore worth the extra time and energy that is required. ${ }^{63}$ This study shows that memorization is not one dimensional, is a topic of interest for improvement, and requires incorporating a variety of techniques simultaneously to achieve optimum results, with individual pianists finding those methods that work best for security and effective musical communication.

${ }^{63}$ Alys Terrien-Queen, "Practicing to Play by Memory," American Music Teacher 44, Aug/Sept 1994, 20. 


\section{BIBLIOGRAPHY}

\section{Works Consulted}

Strunk Jr., William and E. B. White. The Elements of Style, $4^{\text {th }}$ ed. Needham Heights: Allyn \& Bacon, 2000.

Turabian, Kate. A Manual for Writers of Term Papers, Theses, and Dissertations, $7^{\text {th }}$ ed. Chicago: The University of Chicago Press, 2007.

\section{Search Engine}

Google. <http://www.google.com/.

\section{Databases}

Journal of Research in Music Education. <http://www.jstor.com/, 2009, 2010.

The Music Index. <http://www.ebscohost.com/, 2009, 2010.

OCLC WorldShare. <http://www.oclc.org/us/en/default.htm, 2009, 2010.

ProQuest Dissertations and Theses. <http://www.proquest.com/en-US/, 2009, 2010.

Répertoire International de Littérature Musicale. <http://www.rilm.org/, 2009, 2010.

West Virginia University Libraries. <http://libraries.wvu.edu/, 2009, 2010.

\section{Websites}

Alfred Music Publishing. <http://www.alfred.com/, 2011.

All Music. <http://www.allmusic.com/, 2011.

The American Matthay Association for Piano. <http://www.matthay.org/, 2011.

Bach Cantatas. <http://www.bach-cantatas.com/, 2011.

The Canadian Encyclopedia/The Encyclopedia of Music in Canada. $<$ http://www.thecanadianencyclopedia.com/, 2011. 
Dario Diaz, Attorneys at Law. <http://www.dariodiazlaw.com/, 2011.

DRAM. <http://www.dramonline.org/, 2011.

Educational Researcher, Sage Journals. $<$ http://edr.sagepub.com/, 2011.

Indiana University, Jacobs School of Music, Bloomington. $<$ http://music.indiana.edu/, 2011.

Indiana Wesleyan University. <http://www.indwes.edu/, 2011.

Institute of Education, University of London. <http://www.ioe.ac.uk/, 2011.

Iowa State University, Department of Music \& Theatre. <http://www.music.iastate.edu/, 2011.

Lutheran Music Program. <http://www.lutheransummermusic.org/, 2011.

McGill University. <http://www.mcgill.ca/, 2011.

Murray McLachlan, pianist. <http://www.murraymclachlan.com/, 2011.

Music Meets Science. $<$ http://www.iplevents.org/mms/, 2011.

The New Georgia Encyclopedia. <http://www.georgiaencyclopedia.org/, 2011.

New York University, Department of Psychology. <http://www.psych.nyu.edu/, 2011.

North Iowa Area Community College, Music Department. <http://www.niacc.edu/music/, 2011.

Northwest Nazarene University. <http://www.nnu.edu/, 2011.

Piano Pedagogy Forum. <http://www.music.sc.edu/ea/keyboard/ppf/, 2009.

Royal College of Music, Centre for Performance Science. $<$ http://rcm.academia.edu/Departments/Centre_for_Performance_Science/, 2011.

Royal Holloway University of London. <http://www.rhul.ac.uk/, 2011.

Royal Northern College of Music. <http://www.rncm.ac.uk/, 2011.

Southern Methodist University. <http://www.smu.edu/, 2011.

Stewart Gordon, composer. <http://stewartgordon.com/, 2011.

Texas State University, School of Music. <http://www.music.txstate.edu/, 2011.

Texas Tech University, School of Music. <http://www.depts.ttu.edu/music/, 2011. 
Thomas Mastroianni, pianist. <http://thomasmastroianni.com/, 2011.

University of Houston, Moores School of Music. < http://www.music.uh.edu/, 2011.

University of Minnesota, School of Music. <https://music.umn.edu/, 2011.

The University of Oklahoma. <http://www.ou.edu/web.html/, 2011.

The University of Texas at Austin, Butler School of Music. $<$ http://www.music.utexas.edu/, 2011.

Virginia Wesleyan College. <http://www.vwc.edu/, 2011. 